\title{
Present and Future of Flexible Automation: Towards New Paradigms
}

\author{
F. Jovane ${ }^{1}$ (1), Y. Koren² (1), C.R. Boër ${ }^{1}$ (1) \\ ${ }^{1}$ ITIA-CNR, Institute of Industrial Technologies and Automation - National Research Council of ITALY \\ Viale Lombardia 20/A, 20131 Milano, Italy \\ 2 ERC/RMS, College of Engineering - University of Michigan \\ 2350 Hayward St., Ann Arbor, Michigan, USA
}

\begin{abstract}
Automation has been one of the key drivers of the modern Manufacturing Industry and it has been present in various forms from the beginning of the industrial era until today passing through different evolutions responding to human's needs. Therefore automation and the manufacturing industry have undergone several paradigm changes in the last century. They were driven by the market conditions and society needs and were realized by timely developed engineering enabling technologies that fitted the paradigm requirements. This paper maps the different paradigms in terms of market and societal drivers and process technology enablers in order to show a consistent model of paradigm development, a model that links the product, and the process with the appropriate business model. The Flexible Manufacturing Systems (FMS) have been especially analysed as the major enabler to the mass customization paradigm. Summing up, a mapping methodology, able to map all past, present and future production paradigms, is presented. An example on the footwear sector has also been mapped and presented. The analysis is based on a survey conducted in Europe and the USA mechanical industries during 2002. The analysis, carried out within the CIRP Working Group on "Flexible Automation - Assessment and Future" has shown that new paradigms are emerging beyond flexible automation, paradigms that require addressing new technological challenges. Developing these new enabling technologies requires the establishment of new national RTD programmes. Therefore, the role of past national RTD programmes in developing previous enabling technologies that eventually elevated human wealth and life quality is also briefly mentioned. Foresight scenario building and "roadmapping" activities -taking place in different relevant economic regions- are presented. They point to new paradigms and technologies to be developed and call for new RTD programmes to be launched.
\end{abstract}

\section{Keywords:}

Manufacturing, Flexible Automation, Technology Foresight.

\author{
List of acronyms used: \\ NEST: Nature, Economy, Society, Technology \\ M-I VC: Man-Industry Value Chain \\ TPs: Transformation Processes \\ ETs: Enabling Technologies \\ hETs: human Enabling Technologies \\ aETs: artificial Enabling Technologies \\ R-I VC: Research-Innovation Value Chain \\ FMS: Flexible Manufacturing Systems \\ RMS. Reconfigurable Manufacturing Systems \\ RTD: Research, Technological Development
}

\section{INTRODUCTION}

Automation has been and still is the key driver of the transformation of production, from its birth as a modern industrial revolution to the present and the future. All production activities, whatever they are in push or pull economical markets, are a careful balance between a fixed and a flexible automation. In order to assess the past, present and future of flexible automation, it is necessary to evaluate the production paradigms, the respective drivers and enablers and how they interact with the human and industrial life cycle.

These aims will be addressed in this paper, based on the work carried out by the CIRP Working Group A/M/O on "Flexible Automation - Assessment and Future". This working group considered the exploration of new paradigms and surveyed their industrial implementations, specifically focusing on Flexible Manufacturing Systems (FMS) and assessing the role of national and supranational RTD programmes and initiatives.

Manufacturing industry since its birth -two centuries agohas undergone several revolutions, followed by improvement periods, induced by various drivers, from economy (market) to society (environment), to technology (R\&D based innovation).

Throughout such a process, several industrial paradigms have been developed to respond to Natural, Economical, Social and Technological (NEST) context changes and, consequently, demand changes, that can hence be considered as the drivers of evolution.

In turn, these paradigms have contributed to change the context, according to a mutual impact mechanism where R\&D programmes (both public and private) play a crucial role for innovation.

Manufacturing covers the Man-Industry Value Chain (M-I $\mathrm{VC}$ ), ranging from man's needs to industry response, through products, processes and services provided by enterprises. It plays a very important role concerning wealth, creation of jobs (directly as well as through related services) and quality of life. In Europe, for instance, manufacturing accounts for 40 million jobs directly and 80 
million through different services. Its turnover is 4000 Billion EURO.

Driven by the NEST context changes, the M-I VC evolution during the last 50 years has been based, among other factors, on RTD innovation of industrial paradigms -from Flexible Automation to the incoming Sustainable Production- and related Transformation Processes (TPs) and Enabling Technologies (ETs). Such an innovation -in many cases- has been induced and supported by national and supranational RTD programmes, initiatives and funds.

The NEST context is expected to undergo great changes which will call for new RTD based innovation within the M-I Value Chain. The NEST changes will span from man's new needs, to new domains such as bio and nanotechnologies, to new environmental requirements, to the relocation and restructuring of the industrial "fabric" within a growing globalization. Such NEST context changes will impact Manufacturing and require new visions and actions by RTD actors, i.e. institutions, universities, research institutes and centres, companies.

Despite such a context, the overall attention of the institutions towards the M-I VC manufacturing scenario has been decreasing with time [1]. Nowadays institutions are focusing on some specific new areas, without catching the relevance of a holistic approach to promote and sustain manufacturing RTD.

Provided such a vision, the aim of this paper is to:

- Introduce a reference model for the analysis. It represents the interaction, along the M-I VC, between NEST context changes and industry, which respond through manufacturing paradigms. They are supported by RTD based evolution and education processes. This will be addressed in paragraph 2 .

- Analyse - using the model developed - the historical and technological evolution of production paradigms, from rigid to flexible automation to the incoming sustainable production, driven by NEST context changes and supported by RTD Programmes and Initiatives. This will be addressed in paragraph 3.

- Present new manufacturing paradigms, as emerging from foreseen scenarios, calling for new RTD investments and the role of the actors concerned. This will be addressed in paragraph 4 .

\section{REFERENCE MODEL FOR THE ANALYSIS}

In this section, a reference model [2], describing the $\mathrm{M}-\mathrm{I}$ $\mathrm{VC}$, is presented. It represents the macro components linking man's needs to the industrial "fabric" responding to them, considering the drivers and the enablers for the mechanism.

\subsection{Man-Industry Value chain: role played by TPs}

Man-Industry Value Chain (M-I VC) may be represented as shown in Figure 1.

This shows that man's needs are fulfilled, throughout his life, by services provided by Transformation Processes (TPs). This represents the initial basic assumption in building the model described below.

TPs require artificial Enabling Technologies (aETs), such as products, and natural Enabling Technologies (hETs), such as human competences. The aETs and hETs are provided, respectively, by Manufacturing and Education.

Any TP can be represented, using the IDEF-O representation [3] as shown in Figure 2, in terms of:

- Input / output: materials, energy, information

- Means

- Controls

- Transformation Technologies
This approach enables to represent from a single elementary Transformation Process (TP) to a very large number of interrelated TPs, as for the production of a car.

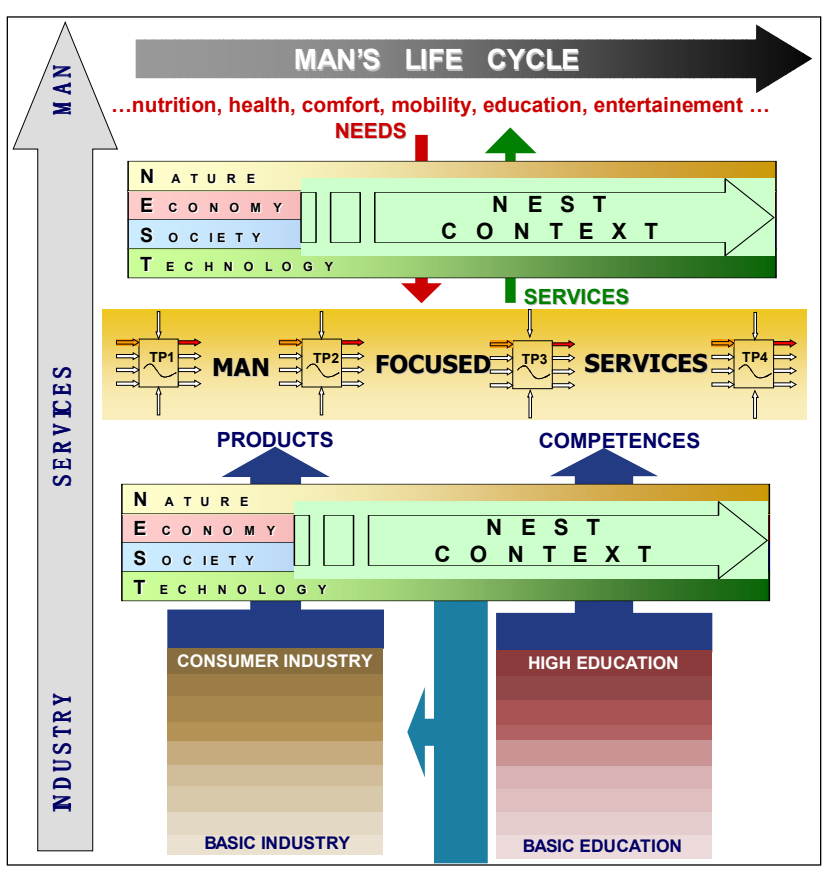

Figure 1: Man Industry Value Chain (M-I VC).

Any TP, during its Life Cycle (see Figure 2), provides services to the entity, natural (man) or artificial (product), to be transformed by inducing a species, a space or a time transformation [4]. A TP may be managed by an individual or a technological organization.

\section{M-I VC: from man's needs to man's focused services.}

This section focuses on the upper part of Figure 1, linking Man's needs to corresponding services provided by TPs.

Man's main needs are, for instance, nutrition, health, education, comfort, mobility, entertainment and so forth.

Such a demand is responded by services provided by Transformation Processes (TPs). These may be classified in four basic types, covering the entire range of possible TPs.

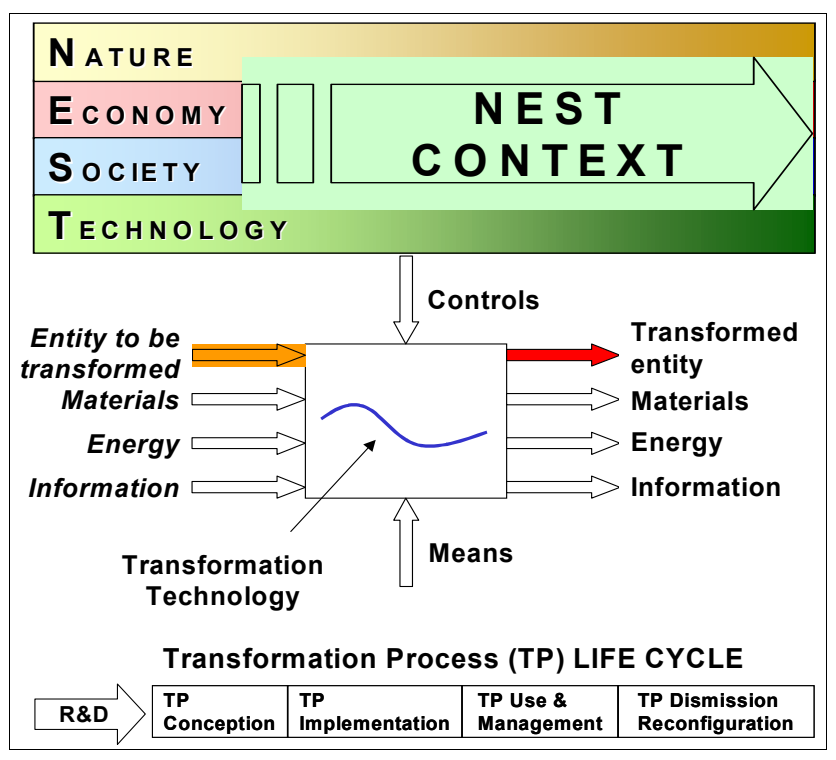

Figure 2: IDEF-0 representation of a Transformation Process (TP), within a given NEST context. 
Referring to Figure 1, such Transformation Processes as TP1 and TP2 are those based on human Transformation Technologies (hTTs), aided respectively by human ETs (TP1) and artificial ETs (TP2).

TP3 and TP4 are those based on artificial Transformation Technologies (aTTs), aided respectively by human ETs (TP3) and artificial ETs (TP4).

The aETs come from the industry, while hETs come from education.

Figure 2 provides the IDEF-0 [4] representation of a Transformation Process (TP). This is composed by a Transformation Technology (TT), either artificial or human, that is enabled by ETs (input/output, means or controls), either artificial or human.

Negotiation between man's needs (demand) and services (response), provided by TPs (as above reported), is driven and controlled by the NEST context concerned.

In such a way, the link between man's needs and the corresponding services provided by TPs can be modelled.

\section{M-I VC: from consumer to basic Industry.}

This section focuses on the lower part of Figure 1, describing a twofold sequence of "stages", covering from the consumer to the basic industry supporting it, from the competences to the education process supporting them.

Each "stage" provides, as demanded, products (aETs) to the downstream "stages" and requires competences (hETs) and products (aETs), respectively, from the education system and the upstream industrial stages.

Figure 3 shows the life cycle of a Product (aET), which is needed by Transformation Processes of the next "stages", such as stage $n+1$.

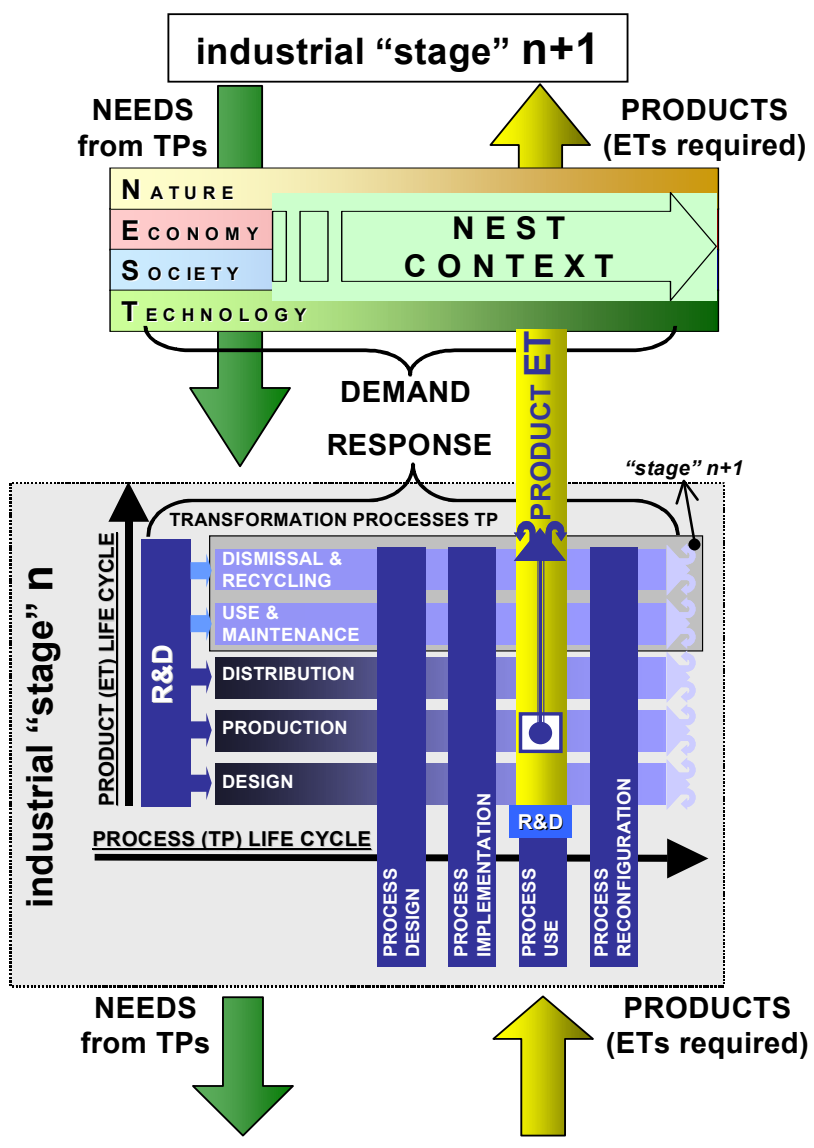

Figure 3: Typical $n^{\text {th }}$ industrial "stage" along the ManIndustry Value Chain (M-I VC).
Some Transformation Processes (TPs) -design, production, distribution- take place within "stage" $\mathrm{n}$, whereas the use process -with the related maintenance and dismissal- takes place within "stage" $n+1$. The life cycle of TPs is also shown as a horizontal component sustaining product (aET) life cycle.

Figure 3 shows that demand, i.e. product (aETs) needs from $\mathrm{n}+1$ TPs processes, and response, i.e. products (aETs) coming from nTPs processes, are controlled by the NEST context and "meet" along the M-I VC, marking the interaction between two stages. Any change in the NEST context (demand) will require a change in response. In turn, new responses may induce changes in the NEST context.

The above may take place at two levels:

- General/conceptual level, making up the conceptual interaction between NEST context "demand paradigms" and industrial "response paradigms".

- Operational level, making up manufacturing activities, within current NEST context "demand paradigms" and industrial "response paradigms".

Finally, the M-I VC may be seen as the "locus" of a long sequence of demand-response "transactions" at a conceptual and at an operational level. The model described provides a thorough representation of this mechanism.

Paradigms may be considered as macro-features describing the M-I VC and its evolution. It is hence important to describe the historical and technological evolution of the paradigms.

\subsection{Evolution of the Man-Industry Value Chain}

The evolution of the M-I VC has and is being driven by man's needs evolution and NEST context changes, asking for new responses from industry.

The "response paradigms" have evolved starting from handicraft manufacture, moving to industrial manufacture and to RTD based Industry nowadays. Experience, discoveries, inventions and, then, RTD activities, were and are the enablers for "response paradigms", their related TPs and ETs, as well as their evolution.

Beginning in the 19th century and increasing during the Second World War, R\&D systematic activities were and are among the major enablers (market pull) and, in some cases, the drivers (technology push) of significant and radical innovation of the industrial paradigms.

Changes within a current "demand paradigm", leading to a new one, may be seen as drivers for the development of a new "response paradigm" and its related TPs and ETs, which may occur either through progressive improvements of a current paradigm or through radical major evolutions to a new paradigm. Several paradigms can of course coexist at the same time and/or in different places according to the evolution of the society and its NEST.

As a new "response", at any "stage" along the M-I VC, may be based on RTD, it is necessary to connect the M-I VC to the Research-Innovation Value Chain (R-I VC), which operates to generate new paradigms and related TPs and ETs.

The R-I VC, which is described in Figure 4 with its macro components, represents the mechanism supporting the evolution process. In particular, by supporting the technological progress through paradigms adequately responding to the evolving NEST context, the R-I VC represents the instrument promoting the evolution of the $M-I V C$ described in Figure 1. It directly impacts each of the highlighted "stages" and their supporting education process, enabling them to provide the new responses better fitting the context changes. 
As shown in Figure 4, the R-I VC supports the evolution process of new technologies all along their lifecycle, made up of different stages of development, from Science to Industrial Innovation. Such a development process is by no means linear.

The actors involved in the R-I VC range from Institutions (setting up RTD policies and conceiving and launching Programmes and Initiatives), to public and private actors such as Universities, Research Institutes and Centres and Companies carrying out RTD as well as education and advising foresight activities.

The foresight process represents the strategic activity producing "scenarios" for the actors involved. Foresight may be seen as a systematic, participatory, future intelligence gathering and medium-to-long-term visionbuilding process aimed at present-day decisions and mobilizing joint actions. This may be done by developing R\&D "Roadmaps" that define paths to the future determined by the expected evolution of the NEST context.

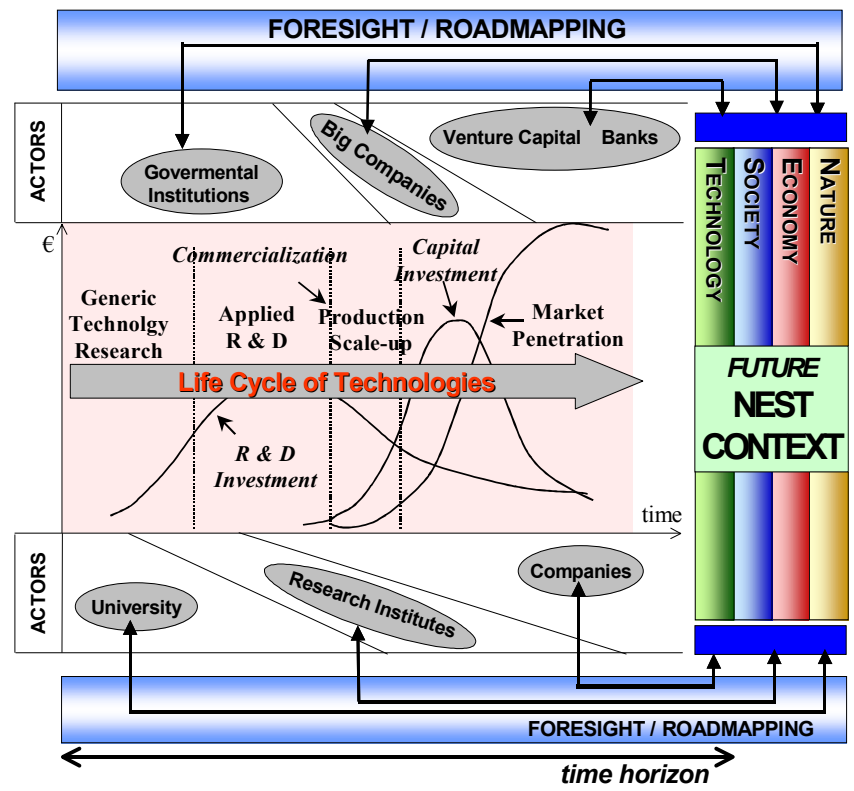

Figure 4: R-I VC, Research-Innovation Value Chain.

The described actors, from Universities to Institutes and Research Centres, may be considered on one hand as experts and advisers for governmental RTD Institutions, and on the other hand as the performers of RTD activities.

Besides describing the working mechanism which is the basis of the R-I VC, Figure 4 also reports the different time horizons of the actors involved in it, both for the performers (lower part) and for the Institutions (upper part)

Such a highly complex Research-Innovation process should lead to new Paradigms and related TPS and ETs responding to NEST context needs as they emerge from the scenarios obtained through the foresight "roadmapping" process.

In this context RTD governmental Programmes and Initiatives may be considered as promoters and sustainers of the development of industrial "response paradigms" and related TPs and ETs, as will be further described in paragraph 3.3.

The model presented so far will now be used for analysing the past-current (paragraph 3) and the future (paragraph 4) of the flexible automation and of the "entities" related to it.

\section{FLEXIBLE AUTOMATION: FROM PAST TO} PRESENT

The model previously presented and the macro components and links highlighted in it may now be used to:

- Assess "response" production paradigms against NEST context demand Paradigms (paragraph 3.1).

- Show their evolution and study a specific application (paragraph 3.2).

- Show the contribution of supranational and national RTD programmes to paradigms evolution (paragraph 3.3).

\subsection{Assessment of production paradigms}

A technological paradigm may be assessed as an integrated and finalized set of enablers to respond to a set of context needs. A new paradigm may develop through experience and/or RTD activities. It starts in a specific time and context, and may coexist with past and new paradigms, in different technological and geographical "locations" [5].

In this paper we will consider the main production paradigms, from Fixed Automation onwards, showing:

- when they were born;

- how they relate to context drivers;

- which enablers they are "made" of;

In order to map the production paradigms that emerged during the years, the basic common necessities driving their beginning must be highlighted. The final goal is to come up with considerations concerning past and present trends, eventually aiming at foreseeing future necessities.

According to the proposed model, the context can be considered as the driver for the evolution, as it changes during the years, defining new necessities and hence TPs (providing the necessary services) composed of new TTs and ETs. This means that the time can be a first suitable category to map the production paradigms.

As specified in the model, the context is made up of such elements as existing technologies, society and market. As widely agreed, the most relevant tendency that occurred during the years moved from the request for high volumes of undistinguished products to be sold at widely affordable prices, to the current request for customized, continuously changing products. In parallel, in the society the request for environmentally friendly products became more and more important, also pushing for continuous modification of environmental laws and, hence, of products. Four main requirements, hence, emerged, during the years, driven by market competition and society:

- need for lower prices;

- need for customization;

- need for innovation;

- need for environment consciousness

Such requirements impacted production inducing three main common necessities, which were faced by different production paradigms:

- productivity;

- customization;

- agility;

The production paradigms that emerged during the years can be grouped according to these basic common necessities. As previously highlighted in paragraph 2.2, the mechanism connecting "demand paradigms" (defined by the NEST context and highlighted by foresight and road mapping activities) to "response paradigms" (implemented by the industry through education and R\&D programs) can 
be approached at two levels, conceptual and operational, as described below.

\section{Conceptual level assessment}

At this level of approach, production paradigms can be assessed as production strategies adopted to cope with context needs.

In modern times, four production paradigms can be identified in the consumer goods manufacturing: Craft Production, Mass Production, Flexible Production and Mass Customization. Below we briefly elaborate on these paradigms.

Craft Production Craft production means to make exactly the product that the customer asks for, usually one product at a time. The customer first pays for the product (at least a partial payment), then the product is designed for the customer, and only then it is made. That means that the craft producer is using a pull-type business model: Sell, Design, Make, Assemble. The craft producer utilizes high skill workers and simple, but flexible machines to produce the products.

Mass Production Mass production means to produce extremely high quantities of identical products, and selling them to customers that will always be there to buy them. Because of the large quantities, products can be produced at a low cost, which, in turn, increases the number of people who can afford to buy the product. Therefore, Mass Production implements a push-type business model: Design, Make, Assemble, Sell. This business model can flourish as long as demand will exceed the supply.

The invention of the moving assembly line by Henry Ford in 1913 marks the beginning of this paradigm, which flourished during most part of the 20th Century requiring machinery to substitute human skills in such production systems as Dedicated Machining Lines (DMLs).

Flexible Production was introduced in the 1970s in order to respond to a change in the market, that started to be saturated by mass produced goods, and a request for more diversified products. The lot size decreased as the products were introduced more and more frequently on the market trying to adapt themselves to the taste of the customer. The mixed type business model Push-Pull: design-make-sell-assemble dominates this paradigm. The components of the products are still produced following the Mass Production paradigm but they are assembled only after the client has decided some optional.

Mass Customization and Personalization means to produce a variety of almost-customized products at massproduction prices. It is a society-driven paradigm, as customers are asking for a larger variety in consumer products. They can get what they want because the market condition has changed since the 1990's from demand exceeding the supply, to the supply exceeding the demand. This Mass Customization and Personalization paradigm is driven by globalization, intended as the creation of a single, worldwide market. Globalization creates a huge excess global production capacity of high quality products that can be produced in many countries. (For example, in 2002 the worldwide capacity of automobile production was 80 million vehicles, while only about 50 million vehicles were sold) These circumstances created a situation in which consumers have more power not only in choosing exactly the product that fits their needs and taste, but also in ordering it and getting it in a reasonable time.

Dell Computers is an example that proves how IT and Internet assist in making the business in this paradigm. Computers, however, are simple products compared to cars, for example. The automotive industry must cope with large fluctuations in product demand caused by the current global excess production capacity. The technological tools that enable industry to compete in this environment are a new type of systems, i.e. Reconfigurable Manufacturing System (RMS), that have a production capacity that can be rapidly adapted to market demand.

This current paradigm is based on a pull-type business model: Sell, Design, Make, Assemble. Dell Computers, for example, first sells the computer, then designs its architecture, and only then assembles it and delivers the customized computer. Utilizing the advanced Information Technology and the Internet, which became a commercial tool at the turn of the 20th Century, enables this paradigm.

\begin{tabular}{|c|c|c|c|c|c|}
\hline Paradigm & $\begin{array}{c}\text { Craft } \\
\text { Production }\end{array}$ & $\begin{array}{c}\text { Mass } \\
\text { Production }\end{array}$ & $\begin{array}{c}\text { Flexible } \\
\text { Production }\end{array}$ & $\begin{array}{c}\text { Mass } \\
\begin{array}{c}\text { Customization } \\
\text { and }\end{array} \\
\text { Personalization }\end{array}$ & $\begin{array}{l}\text { Sustainable } \\
\text { Production }\end{array}$ \\
\hline $\begin{array}{l}\text { Paradigm } \\
\text { started }\end{array}$ & $\sim 1850$ & 1913 & 1980 & 2000 & $2020 ?$ \\
\hline $\begin{array}{l}\text { Society } \\
\text { Needs }\end{array}$ & $\begin{array}{l}\text { Customized } \\
\text { products }\end{array}$ & $\begin{array}{l}\text { Low cost } \\
\text { products }\end{array}$ & $\begin{array}{l}\text { Variety of } \\
\text { Products }\end{array}$ & $\begin{array}{l}\text { Customized } \\
\text { Products }\end{array}$ & $\begin{array}{c}\text { Clean } \\
\text { Products }\end{array}$ \\
\hline Market & $\begin{array}{l}\text { Very small } \\
\text { volume per } \\
\text { product }\end{array}$ & $\begin{array}{c}\text { Demand > } \\
\text { Supply } \\
\text { Steady demand }\end{array}$ & $\begin{array}{l}\text { Supply > Demand } \\
\text { Smaller volume } \\
\text { per product }\end{array}$ & $\begin{array}{l}\text { Globalization } \\
\text { Fluctuating } \\
\text { demand }\end{array}$ & Environment \\
\hline $\begin{array}{c}\text { Business } \\
\text { Model }\end{array}$ & $\begin{array}{c}\text { Pull } \\
\text { sell-design- } \\
\text { make-assemble }\end{array}$ & $\begin{array}{c}\text { Push } \\
\text { design-make- } \\
\text { assemble-sell }\end{array}$ & $\begin{array}{c}\text { Push-Pull } \\
\text { design-make- } \\
\text { sell-assemble }\end{array}$ & $\begin{array}{c}\text { Pull } \\
\text { design-sell- } \\
\text { make-assemble }\end{array}$ & $\begin{array}{c}\text { Pull } \\
\text { Design for } \\
\text { environment-sell- } \\
\text { make-assemble }\end{array}$ \\
\hline $\begin{array}{c}\text { Technology } \\
\text { Enabler }\end{array}$ & Electricity & $\begin{array}{l}\text { Interchangeable } \\
\text { parts }\end{array}$ & Computers & $\begin{array}{l}\text { Information } \\
\text { Technology }\end{array}$ & $\begin{array}{c}\text { Nano/Bio/Material } \\
\text { Technology }\end{array}$ \\
\hline $\begin{array}{l}\text { Process } \\
\text { Enabler }\end{array}$ & Machine Tools & $\begin{array}{c}\text { Moving } \\
\text { Assembly Line \& } \\
\text { DML }\end{array}$ & FMS Robots & RMS & $\begin{array}{l}\text { Increasing } \\
\text { Manufacturing }\end{array}$ \\
\hline
\end{tabular}

Table 1: Evolution of production paradigms. 


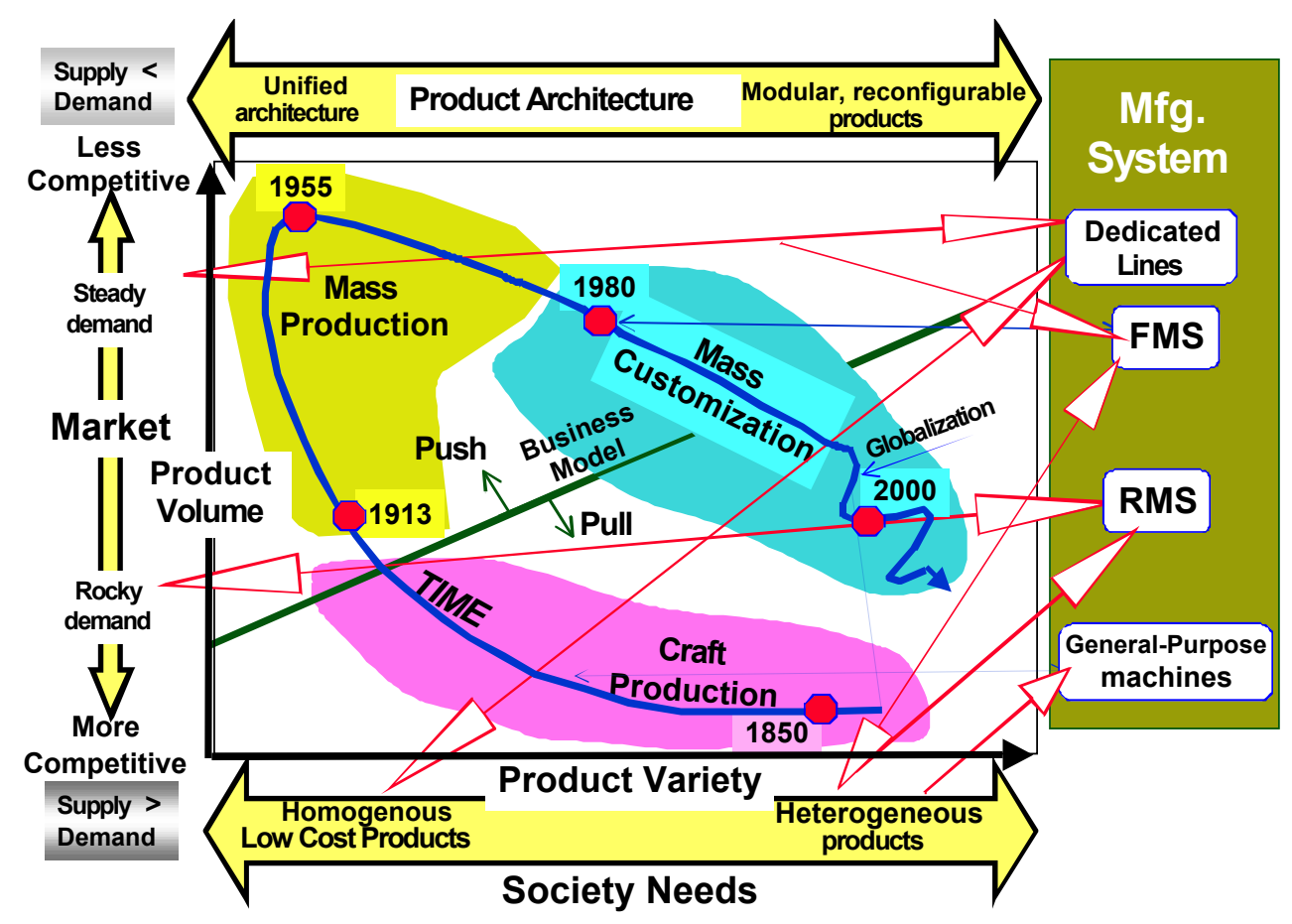

Figure 5: Paradigms and manufacturing systems related to market and society.

As we see, each manufacturing paradigm has a different driver that originates either from society needs or from the market conditions at the paradigm period. We have also seen that each paradigm has a technology enabler of very different type, and a different manufacturing system (which is the process enabler) that fits the paradigm principles.

Furthermore, each paradigm has its business model that fits the paradigm in addressing society needs and market conditions. All these factors are summarized in Table 1.

In the table, the new emerging paradigm of Sustainable Production is also reported, which is based on society needs for a better environment and therefore "clean products".

The new emerging technologies of nano, bio and material technology alone or combined will provide the possibility to attain this requirements, and the process enabler of Increasing Manufacturing (based on adding atom to atom) will become the breakthrough strategy to realize the goals of society in 2020 and on.

Figure 5 shows how paradigms and their corresponding manufacturing systems are developed with the changing society needs and market requirements.

Globalization means not only that large companies are becoming global in terms of their production facilities and sales, but also that those companies:

- Must produce a variety of innovative products to supply customers' taste and preferences in different countries or regional segments with a variety of personal preferences within each region. This trend towards personalized production can be met only if products become more modular, and even reconfigurable to some degree.

- Must cope with large fluctuations in product demand caused by the current global excess production capacity; this could be done by utilizing reconfigurable manufacturing systems that have a production capacity adaptable to market demand.

- Should develop new business models that take advantage of the opportunities provided by the Internet to move towards pure pull-type business models that enhance sales and customer relationships and enable a rapid response to customer needs. The rapid response comprehends also the capability to introduce new products within short windows of opportunity, which can be done by building virtual enterprises that can be formed and dissolved according to opportunities.

By considering also these factors, Figure 5 shows a comprehensive model illustrating the relationships in four paradigms between input drivers - market and society needs - process enablers (i.e., the type of manufacturing systems), the product architecture, and a simplified business model. This model shows how production paradigms shift with time.

It is necessary to notice that the time periods in Figure 5 fit the Western World, in which the current paradigm of mass customization and personalization started around the year 2000 , and it is coupled with the market fluctuations occurring with globalization. However, it is necessary to consider that, for example, the internal Chinese market is just entering now the mass-production era. That means that Chinese manufacturing companies need to possess a wide-range portfolio consisting of DMLs, FMSs, and RMSs to respond to internal needs simultaneously with exporting consumer goods to the global market.

The Sustainable Production paradigm will still shift the loop in a direction difficult to predict yet.

\section{Operational level assessment}

A parallel mapping can be conducted at an operational level, where the enablers developed to cope with the production concepts previously described, must be assessed. In this case, hence, the specific technologies and practices developed to implement the production paradigms previously described can be analyzed. According to the proposed model, this refers to mapping the TPs, ETs, developed through the R-I VC.

Considering the three main described categories of necessities driven by market competition and social trends, three main corresponding areas of research can be highlighted: Automation, Mass Customization and Agile Production. Each of them corresponds to specific production paradigms that have emerged during the years, 
and that can consequently be mapped according to the proposed scheme summarized in Table 2.

\begin{tabular}{|c|c|c|}
\hline Aim & $\begin{array}{c}\text { Research } \\
\text { area }\end{array}$ & $\begin{array}{c}\text { Enabling operational } \\
\text { paradigm }\end{array}$ \\
\hline Productivity & Automation & $\begin{array}{c}\text { Fixed automation } \\
\text { Programmable automation }\end{array}$ \\
\hline \multirow{3}{*}{ Customization } & $\begin{array}{c}\text { Mass } \\
\text { Customization }\end{array}$ & $\begin{array}{c}\text { Flexible Automation } \\
\text { Lean Production } \\
\text { CIM }\end{array}$ \\
\hline Agility & & Virtual Enterprise \\
& Agile & $\begin{array}{c}\text { Holonic Manufacturing } \\
\text { Reconfigurable } \\
\end{array}$ \\
& Production & Manufacturing \\
& Service Manufacturing \\
\hline
\end{tabular}

Table 2: General aims, research areas and corresponding enabling operational paradigms.

Such traditional paradigms as Fixed and Programmable Automation aimed at coping with the first common necessity, productivity. In general terms, automated transfer lines were the instruments to increase quality and production rates to reduce the final cost per part and hence enable high volumes productions [6].

Flexible automation, Lean production (through the JIT, mixed model and six sigma philosophies), CIM, and Mass Customization cope with the second necessity. These paradigms share the aim of reducing the set up time to shift between different variants, enlarging the mix of parts to be supplied to the market in an economical manner. Customization can hence be considered as the basic common objective pursued by these paradigms, and Mass Customization [7] [8] [9] [10] [11] [12] implements it at the highest degree.

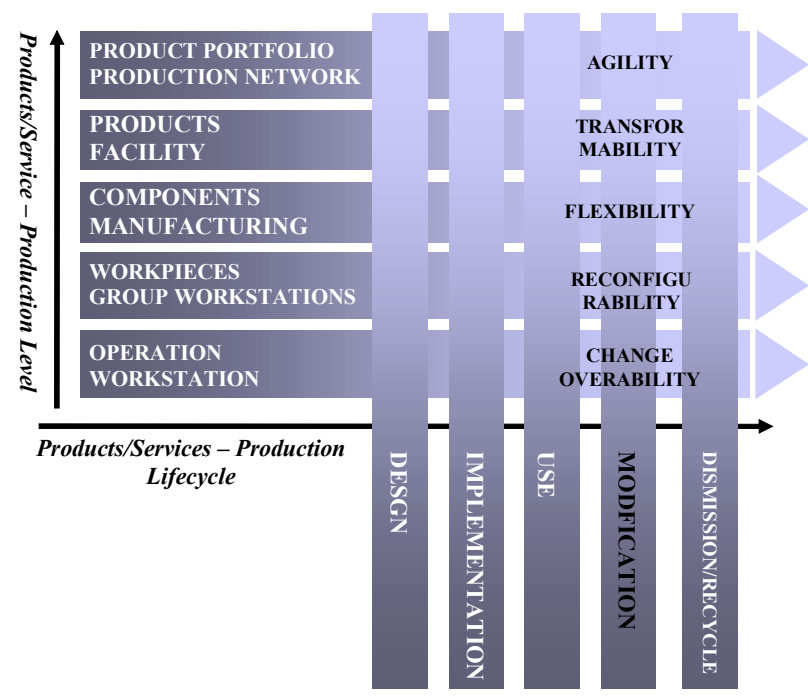

Figure 6: Phases of the lifecycle, paradigms and level of approach.

Agile Production, Virtual Enterprise/Networked Organizations, Holonic Manufacturing, Reconfigurable Manufacturing and Service Manufacturing, though maintaining the previous one as a necessity, mostly cope with the third basic common necessity. The emphasis is on disturbances and frequent changes rather than the mere spectrum of parts, consequently involving the system, as well as product life cycle considerations in the goal of economic effectiveness. Agile Production encompasses such a philosophy in its wider meaning, aiming at enabling companies to catch the opportunities arising in dynamic markets [13] [14] [15] [16] [17] [18].

To complete the mapping, the level of approach characterizing each production paradigm has also to be considered, as different paradigms address the TPs at different levels. The approach proposed concerning Changeability [19] [20] provides a suitable example in stating the link between the level of approach and the phases of the lifecycle addressed by different paradigms, as summarized in Figure 6.

Besides the drivers pushing for the creation of new paradigms, to complete the mapping of the "response" paradigms, an analysis of the ETs for each of them must be carried out.

To this end, the described reference model provides a useful instrument. According to it, in fact, the enablers for each paradigm can be specified in terms of the phase of the life cycle they address and, inside each phase, in terms of the kind of input (material, information, energy), means and control methods they address. As a consequence, the mapping at an operational level can be further described as shown in Figure 7.

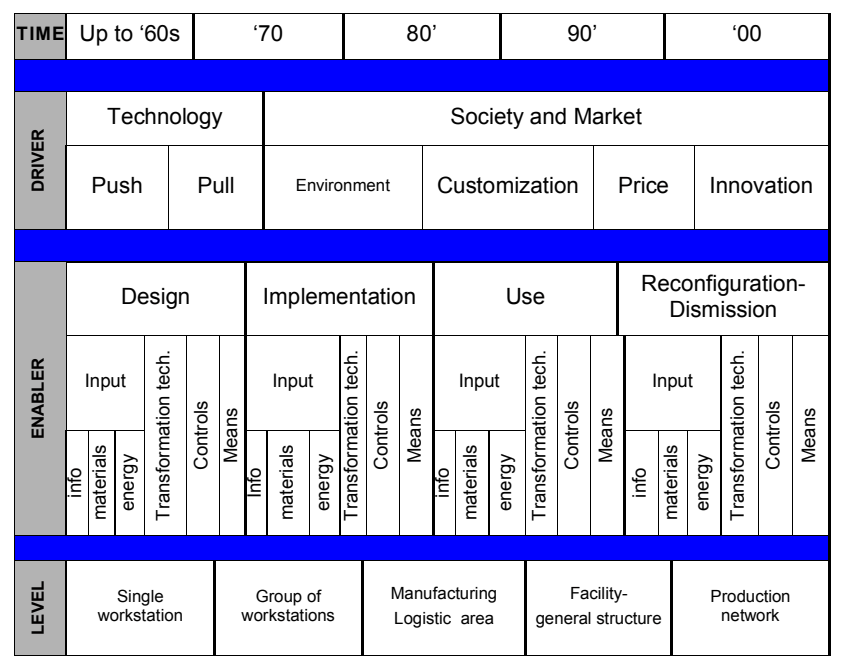

Figure 7: Mapping drivers and enablers of, respectively, NEST context demand Paradigms and Industrial Response Paradigms, at an operational level (TPs, ETs).

The term Automation was introduced [6] by Harder in 1946 to describe the production practices developed, as previously described, to respond to a context oriented towards productivity and repeatable quality. Though introduced in the middle of the 20th century, it is still adopted in several sectors embodied by such production paradigms as Fixed and Programmable Automation [6] [21] [22] [23] [24] [25].

The enablers developed for them mostly impact the TP design (machines, line, control) and use (specialization, use of dedicated stations) phases, mostly addressing means (machines, PLCs) and controls (programmes). The level of approach mostly refers to the single station and the connection between groups of machines.

Flexible Automation [6] [17] [26] [27] [28] [29], which developed at the beginning of the ' 70 s as a research topic and has been adopted as a real application since the ' 80 s, pushes for set up times reduction to enable wide mixes of components, exploiting such enablers as robots and machining centres. The main impact, hence, refers to design (parallel layout, machining centres, FMS) and the 
method adopted in the use phase (unmanned, centralized control).

The paradigm of CIM [30] [31] [32] [33] [34] consists of an "extensive use of computer systems to design the products, plan the production, control the operations and accomplish many of the business-related functions in a manufacturing firm" [6]. It started during the "80s, when computer systems became reality, and were heavily involving the management of information inside the firm.

On the other hand, Lean Production [35] [36] [37] [38] [39] can be considered as a collection of techniques (mostly referred to production management) aimed at using "less of everything compared with Mass Production, less of the human in the factory, less manufacturing space, less of the investment in tools, less in engineering hours to develop a new product in less time. Also, it requires keeping far less the needed inventory on site, results in many fewer defects, and produces a greater and ever growing variety of products" [39].

The paradigms concerned with Agile Production mostly appeared as research topics during the '90s.

The Virtual Enterprise/Networked Organization paradigm [40] [41] [42] [43] [44] is based on the idea of cooperating among industries sharing knowledge and competencies to catch market opportunities. The management of the entire life cycle of the cooperation plays a crucial role for the success (which is typical, as previously stated, of the agility oriented paradigms), from the design to the implementation, the use and the dismissal (after several possible reconfigurations) of the relationship. The focus is on the knowledge-share, hence mostly impacting the information as an input for each phase, but also involving the means to implement the cooperation as well as the cooperation control.

The Holonic Manufacturing paradigm [45] [46] [47] [48] [49] [50] mostly focuses on the control level and, more specifically, on the concept of autonomous cooperating agents (holons) operating in the shop floor. Both the design, the implementation, the use and the reconfiguration of the control are involved in the paradigm.

Reconfigurable Manufacturing [51] [52] [53] [54] [55] [56] [57] impacts the single machine (RMT) as well as the control (distributed controls) and the whole system (RMS), involving the whole TP lifecycle.

Service Manufacturing [8] [58] [59] [60] focuses on the way responsibilities are allocated inside the value creation process, aimed at improving the OEMs agility through suitable contracts signed with Manufacturing Service Providers (e.g. pay per part, pay per use, pay per availability, and other mechanisms as proposed by Seliger [61], Urbani [62] [63] and others [64] [65]). The impact is mostly on means, addressing all the phases of the LC at manufacturing level.

In parallel with the three main drivers considered so far (price, customization, innovation), the environmental consciousness previously mentioned has also played a crucial role in the last decades. Two main effects derive from such a social driver:

- the necessity to frequently update the products;

- the necessity to stress the importance of dismissal and recycling inside the life cycle management;

The first one has already been considered as an innovation aspect, mostly addressed by the production paradigms oriented to Agile Production described so far. The second is mostly addressed in the paradigm of Sustainable Production [66] [67] [68] [69] [70] [71] [72] [73], focusing, for the future manufacturing, on new materials, as well as dismissal and recycling techniques and design for disassembling methodologies.
Summing up, after a conceptual level assessment, a model has been the basis for consistently assessing the development of several paradigms in terms of market and societal drivers as well as of technological enablers. This has been mapped according to the methodology represented in Figure 7. Consequently, an example on a vertical sector (footwear) has also been mapped, as is presented below.

\subsection{Application to the shoe production}

It is clear that the various paradigms described in the previous paragraph are rarely applied individually in the various manufacturing sectors and, actually, few of them coexist according to the drivers applicable to the sector at a specific moment in time and location. Location is also an important factor because the same paradigm could be applied in a certain region of the globe but not in another.

The shoe product and the footwear industry will be taken as an example of the above described concepts. In particular, we will describe the evolution of the drivers and the enablers that sustained the appropriate applicable production paradigm.

The shoe industry has gone through more or less the same market requirements as other products: from a craft (artefact) manufacturing all hand-made to machine-aided and mass production in the ' $60 \mathrm{~s}$. Because the shoe manufacturing still requires a high degree of hand work particularly in the final assembly, the mass production paradigm, required up to the ' $80 \mathrm{~s}$, pushed a de-localization of the manufacturing in low-wages countries (driver "price"). In order to protect their investments and their world market position, the European companies pushed towards more automation and innovation particularly in the product design and machine automation.

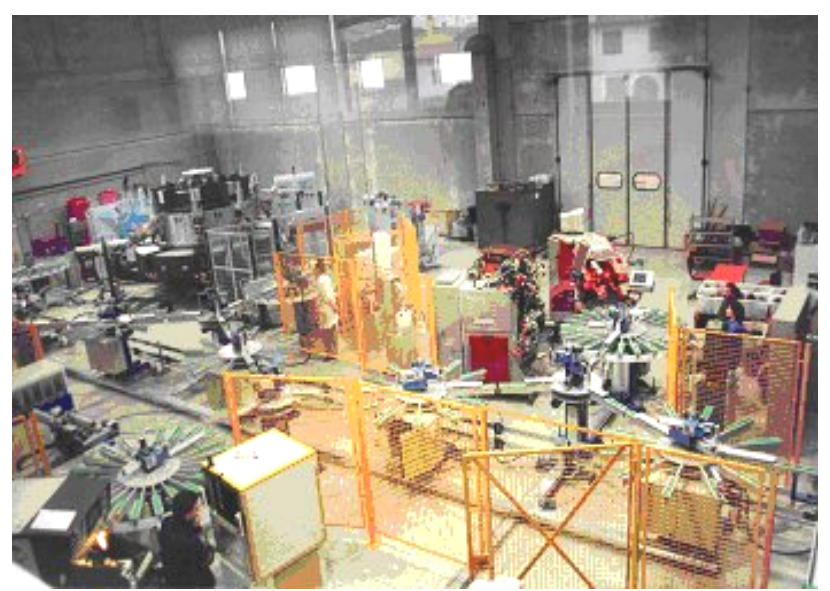

Figure 8: Flexible automated pilot plant for mass customized shoes: Italian National Program for Innovative Production Systems (PNR-SPI6).

The requirements of drivers like "price" and "innovation" generated research projects in this direction such as the National Research Programme for Innovative Production Systems (PNR-SPI) in Italy, that was translated in the footwear sector by the SPI 6 [74] that provided, as a result, the pilot plant shown in Figure 8.

The results of this project (terminated in the middle of the ' 90 s, see Figure 9) were a set of innovative machines with increased flexibility (lot size near 1 but with not such a great variability) and increased knowledge tools for product design (CAD) and manufacturability (CAM). The system approach also pushed towards integration and control innovation. 


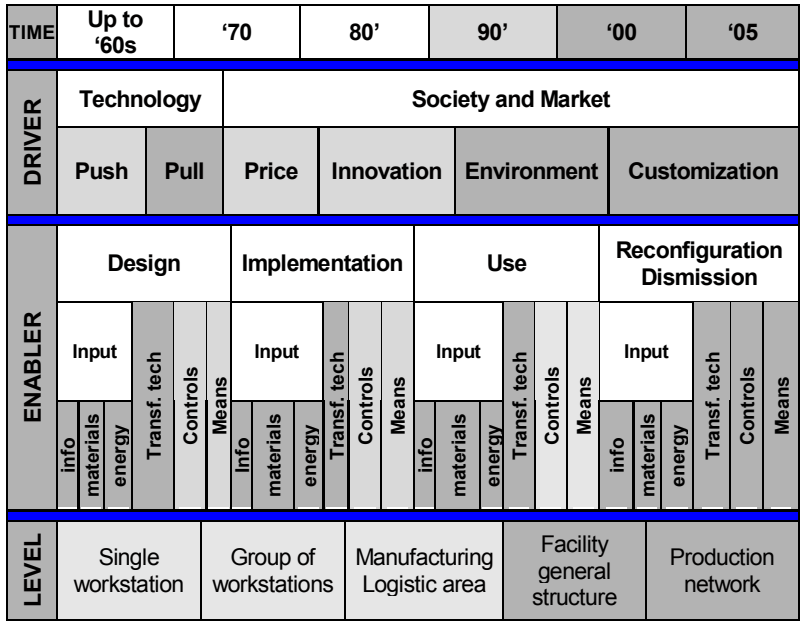

Figure 9: Mapping of the evolution of the production paradigms in the shoe industry: flexibility oriented (SPI 6, light grey), customization oriented (EUROShoE project, dark grey).

The following driver taking importance in the '90s is "customization". The consumer became the centre of all the activities and for the shoe in particular the ability to design the shoe for the individual consumer needs became the centre of the research activities in the footwear sector. Technology enablers in the data capture, data transformation, knowledge based and highly flexible but also reconfigurable machines and production systems were developed in projects like EUROShoE [75] [76], CICLOP, etc (see Figure 9). However, the whole value chain had to be reassessed and also the production control, logistics, production networks (extended enterprise), standardization had to be innovated and highly integrated.

Finally today we are looking at the "environment" as the future driver. Society requires $100 \%$ environmental free products and related processes maintaining the degree of comfort and customization acquired in the present. A proposal for a new R\&D project called CEC-made-shoe (Comfortable Environmental Customized shoe made) has been presented for funding at the European Commission by a large consortium of over 50 partners. The project will look at a set of completely new technologies and innovation ("breakthrough") for the footwear sector aiming at new materials, new embedded ICT, new sensors, new production technologies all human centred but considering the whole life cycle of the human being from babyhood to old age.

It is important to notice also that the new drivers of society and market require a shift in research paradigm from small projects with limited innovation potential ("price" reduction by increased "automation) to larger projects with larger innovation potential (from "mass production" to "mass customization" by increased "flexibility and reconfigurability" and "knowledge based system"). The next step is focused on even larger scale research projects - programmes - with innovation potential to solve huge societal needs like "environment" and the whole life cycle of the human being.

\subsection{The promoting and sustaining role of Manufacturing RTD}

The evolution of Man-Industry Value Chain - and, hence, of manufacturing "response paradigms" - described in paragraph 2.2 relies on RTD based Innovation [77], integrated by continuous improvement as modelled by the R-I VC. To stress this mechanism supporting the described paradigm evolution, the last RTD programmes will be briefly analysed with respect to different regions.

In the past 40 years advanced countries - i.e. USA, Japan, single European Countries and more recently European Union - have launched RTD Programmes leading to the development of:

- "milestones" of the last Industrial Revolution, such as: N/C, CAD, CAE, CIM, FMS;

- new Paradigms and relevant TPs and ETs: from flexible automation to the incoming sustainable production (see paragraph 3.1);

In the last ten years -in the advanced countriesGovernment investments in research and in particular manufacturing RTD has been decreasing, while moving toward medium-long term. In the same period, Industry investment in Manufacturing RTD has been increasing and getting closer to market. New emerging countries have started investing in manufacturing RTD.

Relevant examples - concerning advanced (Japan US, EU) and new emerging countries (China) - are reported in the following paragraphs. They cover from the late ' 70 s up to now, and supported the development of the paradigms dealt with in paragraph 3.1.

\section{Manufacturing RTD Programmes in Japan}

Japan, in 1977, launched the largest RTD initiative to promote the paradigm of Flexible Automation and related TPs and ETs. It was named "The Flexible Manufacturing System Complex provided with laser". Some other Programmes followed since those days [78]. Table 3 shows some of their features.

\begin{tabular}{|c|c|c|c|c|}
\hline & \multirow{2}{*}{$\begin{array}{l}\text { Name of RTD } \\
\text { Programme }\end{array}$} & \multicolumn{3}{|c|}{ MAIN GOAL FOCUS } \\
\hline & & Industry & Society & $\begin{array}{c}\text { RTD } \\
\text { Actors }\end{array}$ \\
\hline 1 & $\begin{array}{l}\text { Flexible Manufacturing } \\
\text { System Complex } \\
\text { provided with Laser } \\
\text { FY1977-1983 } \\
\text { 13BYen }\end{array}$ & $x$ & & \\
\hline 2 & $\begin{array}{c}\text { Advanced Material } \\
\text { Processing and } \\
\text { Machining Technology } \\
\text { FY 1986-1993 } \\
\text { 15BYen }\end{array}$ & $x$ & & $\mathrm{x}$ \\
\hline 3 & $\begin{array}{c}\text { Digital Meister } \\
\text { FY2001-2003 } \\
\text { 6BYen }\end{array}$ & $x$ & & $x$ \\
\hline
\end{tabular}

Table 3: Japan special RTD Manufacturing Programmes launched by MITI, Minister of International Trade and Industry of Japan.

\begin{tabular}{|c|c|c|c|c|c|c|c|}
\hline \multicolumn{4}{|c|}{ Research Results ETs } & \multicolumn{3}{c|}{ Processes concerned TPs } \\
\hline & T T & C & M\&S & E/O & Design & Production & Distribution \\
\hline 1 & $\mathrm{X}$ & $\mathrm{X}$ & $\mathrm{X}$ & & $\mathrm{X}$ & $\mathrm{X}$ & \\
\hline 2 & & & $\mathrm{X}$ & & & $\mathrm{X}$ & \\
\hline 3 & $\mathrm{X}$ & & $\mathrm{X}$ & & $\mathrm{X}$ & $\mathrm{X}$ & \\
\hline
\end{tabular}

Table 4: Japan: special RTD Manufacturing Programmes, TPs and ETs concerned (legenda: TT: Transformation Technology; C: Controls; M\&S: Machinery \& Systems; E/O: Enterprise/Organization).

The related TPs and ETs are schematically summarized in Table 4. 
The technological enabling operational paradigms concerned ranged from flexible automation to holonic systems. Special funds were available for Universities and Research Institutes.

\section{Manufacturing RTD Funds and Programmes in USA}

Several federal programs have supported manufacturing RTD.

The Manufacturing Extension Partnership programmes (MEP) assisted small and medium-sized manufacturers in areas involving technological change [79]. The Advanced Technology Program (ATP) supporting emerging and enabling technologies for improved products and industrial processes.

The Next-Generation Manufacturing (NGM) project was initiated in 1995. As a bottom up, industry-led effort, supported by DOE (Dept. of Energy), DOD (Dept. of Defence), NIST (Inst. Of Standard and Technology), NSF (National Science Foundation), it intended to [80]:

- develop a broadly accepted model of future manufacturing enterprises;

- recommend actions that manufacturers, working individually and in partnership with government, industry, and the academic community, can use to attain world-class status;

Following the Next-Generation Manufacturing Project, ended in 1997, the integrated Manufacturing Technology Roadmapping (IMTR) Initiative -supported by NIST, DOE, NSF and DARPA- was launched in 1998 to develop a R\&D agenda that [81]:

- defines key technologies goals that cross all manufacturing sectors;

- provides focus for concentrated effort to achieve goals;

- promotes collaborative R\&D to deliver solutions to critical requirements.

\section{Manufacturing RTD Programmes in Europe}

In this case, three levels must be considered: European Union, National States, and Regions. The first two will be considered.

\section{European Union Framework Programmes}

The European Commission has promoted and sustained six RTD programmes since 1982 [82].

\begin{tabular}{|c|c|c|c|}
\hline \multirow{2}{*}{$\begin{array}{c}\text { Framework } \\
\text { Programmes }\end{array}$} & \multicolumn{3}{|c|}{ MAIN GOALS FOCUS } \\
\cline { 2 - 4 } & $\begin{array}{c}\text { RTD } \\
\text { Actors }\end{array}$ & Industry & Society \\
\hline $\begin{array}{c}\text { FP1 } \\
1984-1987 \\
3,750 \text { MECU }\end{array}$ & $\bigcirc$ & $D$ & $D$ \\
\hline $\begin{array}{c}\text { FP2 } \\
1987-1991 \\
5,396 \text { MECU }\end{array}$ & & $\bigcirc$ & $D$ \\
\hline $\begin{array}{c}\text { FP3 } \\
1990-1994 \\
6,600 \text { MECU }\end{array}$ & $\bigcirc$ & $\bigcirc$ & $D$ \\
\hline $\begin{array}{c}\text { FP4 } \\
1994-1998 \\
10,254 \text { MECU }\end{array}$ & $\bigcirc$ & $D$ & $\bigcirc$ \\
\hline $\begin{array}{c}\text { FP5 } \\
1998-2002 \\
14,960 \text { MEuro }\end{array}$ & $\bigcirc$ & $D$ & $\bigcirc$ \\
\hline $\begin{array}{c}\text { FP6 } \\
\text { 2002-2006 } \\
17,500 \text { MEuro }\end{array}$ & $\bigcirc$ & $D$ & $D$ \\
\hline
\end{tabular}

Table 5: EU Framework Programmes (, , O, D: focus ranking).
In 1984 the first Framework Programme - structuring and finalizing specific programmes and Initiatives - were launched, as shown in Table 5. The sixth Framework Programme was launched in 2002 to last until 2006.

The various Framework Programmes have promoted and financially sustained RTD activities oriented to the development of new paradigms and related TPS and ETs, at various levels, from machines to extended enterprises, as summarized by Table 6 .

\begin{tabular}{|c|c|c|c|c|c|c|c|}
\hline \multicolumn{6}{|c|}{ Research Results ETs } & \multicolumn{3}{c|}{ Processes concerned TPs } \\
\hline & T T & C & M\&S & E/O & Design & Production & Distribution \\
\hline 1 & X & X & & & X & X & \\
\hline 2 & X & X & & & X & X & \\
\hline 3 & X & X & & & X & X & \\
\hline 4 & X & & X & & X & X & X \\
\hline 5 & X & & X & X & X & X & \\
\hline 6 & X & & X & X & & X & \\
\hline
\end{tabular}

Table 6: EU RTD Manufacturing Programmes, TPs and

ETs concerned (legenda: TT: Transformation Technology; C: Controls; M\&S: Machinery \& Systems; E/O: Enterprise/Organization)

\section{European National Programmes}

Most of the European Countries, since the beginning of the '80s up to now, launched RTD funds addressing the manufacturing field. Some countries launched national programmes, such as Germany and Italy.

\begin{tabular}{|c|c|c|c|}
\hline $\begin{array}{c}\text { Name of RTD } \\
\text { Programme }\end{array}$ & \multicolumn{3}{|c|}{ MAIN GOAL FOCUS } \\
\hline & Industry & Society & $\begin{array}{c}\text { RTD } \\
\text { Actors }\end{array}$ \\
\hline $\begin{array}{c}\text { Research for the Production } \\
\text { of Tomorrow, 1999-2003 }\end{array}$ & $\bullet$ & & \\
\hline $\begin{array}{c}\text { Production 2000, } \\
\text { 1995-1999 }\end{array}$ & $\mathbf{0}$ & $\bigcirc$ & \\
\hline $\begin{array}{c}\text { Quality Management, } \\
\text { 1992-1996 }\end{array}$ & $\bullet$ & & $\bigcirc$ \\
\hline $\begin{array}{c}\text { Manufacturing Technology, } \\
\text { 1988-1992 }\end{array}$ & $\bullet$ & & $\bigcirc$ \\
\hline $\begin{array}{c}\text { Manufacturing Technology, } \\
\text { 1984-1987 }\end{array}$ & $\bullet$ & & \\
\hline $\begin{array}{c}\text { Manufacturing Technology, } \\
\text { 1980-1983 }\end{array}$ & $\bullet$ & $\bigcirc$ & \\
\hline
\end{tabular}

Table 7: German RTD Manufacturing Programmes $(\bullet, O, D$ : focus ranking).

\begin{tabular}{|c|c|c|c|c|}
\hline \multicolumn{5}{|c|}{ Research Results (ETs) } \\
\hline & TT & C & M\&S & E/O \\
\hline 1 & X & & X & X \\
\hline 2 & X & X & X & X \\
\hline 3 & X & X & & X \\
\hline 4 & X & & & X \\
\hline 5 & X & & X & \\
\hline 6 & X & & & X \\
\hline
\end{tabular}

Table 8: German RTD Manufacturing Programmes, ETs concerned (legenda: see Table 6). 
The German Government has launched, starting in 1983, Programmes addressing from manufacturing technologies to quality management [83].

The goal focus of such programmes is shown in Table 7.

The research results concerning ETs, classified following the reference model shown in Figure 2, are reported in Table 8 (concerning ETs), while the concerned TPs are shown in Table 9.

\begin{tabular}{|c|c|c|c|c|c|}
\hline \multicolumn{5}{|c|}{ Processes concerned (TPs) } \\
\cline { 2 - 6 } & Design & Production & Distribution & $\begin{array}{c}\text { Use } \\
\text { Maintenance }\end{array}$ & $\begin{array}{c}\text { Dismissal } \\
\text { Recycling }\end{array}$ \\
\hline 1 & $\mathrm{X}$ & $\mathrm{X}$ & & $\mathrm{X}$ & \\
\hline 2 & $\mathrm{X}$ & $\mathrm{X}$ & & & $\mathrm{X}$ \\
\hline 3 & $\mathrm{X}$ & $\mathrm{X}$ & & & \\
\hline 4 & $\mathrm{X}$ & $\mathrm{X}$ & $\mathrm{X}$ & & \\
\hline 5 & & $\mathrm{X}$ & & & \\
\hline 6 & & $\mathrm{X}$ & & & \\
\hline
\end{tabular}

Table 9: German RTD Manufacturing Programmes, TPs concerned.

Starting in 1983, in Italy the National Research Council has launched such research programmes as:

- the "Targeted Research Programmes on Mechanical Technology" (PFTM-CNR), mostly addressing the FMS development and implementation [84];

- the "Targeted Research Programmes on Robotic Systems" (PFR-CNR), focusing on new robotic systems and applications [85];

Starting from 1995 the Italian Ministry of Education, University and Research (MIUR) launched the National Research Programmes on Innovative Production Systems (PNR-SPI) [2].

Special funds for industrial RTD and university research were made available since 1982.

\begin{tabular}{|c|c|c|c|}
\hline $\begin{array}{c}\text { Name of RTD } \\
\text { Programme }\end{array}$ & \multicolumn{3}{|c|}{ MAIN GOAL FOCUS } \\
\hline & Industry & Society & $\begin{array}{c}\text { RTD } \\
\text { Actors }\end{array}$ \\
\hline $\begin{array}{c}\text { PFTM-CNR (1984-1989) } \\
\text { 15 Meuro }\end{array}$ & $\bullet$ & $\bigcirc$ & $\bigcirc$ \\
\hline $\begin{array}{c}\text { PFR-CNR (1990-1995) } \\
40 \text { Meuro }\end{array}$ & $\bullet$ & $\bigcirc$ & $\bigcirc$ \\
\hline $\begin{array}{c}\text { PNR-SPI (1996-1998) } \\
75 \text { Meuro }\end{array}$ & $\bullet$ & $\bigcirc$ & $\bigcirc$ \\
\hline
\end{tabular}

Table 10: Italian RTD Manufacturing Programmes $(\bullet, O, \mathrm{D}$ : focus ranking).

\begin{tabular}{|c|c|c|c|c|c|c|}
\hline \multicolumn{4}{|c|}{ Research Results (ETs) } & \multicolumn{3}{c|}{$\begin{array}{c}\text { Processes } \\
\text { concerned (TPs) }\end{array}$} \\
\hline & TT & C & M\&S & E/O & design & production \\
\hline PFTM-CNR & $\mathrm{x}$ & $\mathrm{x}$ & $\mathrm{x}$ & & $\mathrm{x}$ & $\mathrm{x}$ \\
\hline PFR-CNR & & $\mathrm{x}$ & $\mathrm{x}$ & $\mathrm{x}$ & $\mathrm{x}$ & $\mathrm{x}$ \\
\hline PNR-SPI & & $\mathrm{x}$ & $\mathrm{x}$ & & $\mathrm{x}$ & $\mathrm{x}$ \\
\hline
\end{tabular}

Table 11: Italian special RTD Manufacturing (legenda: TT: Transformation Technology; C: Controls; M\&S: Machinery \& Systems; E/O: Enterprise/Organization).

\section{The EUREKA Initiative}

The EUREKA initiative [86] has already launched about 2400 market oriented projects, "clusters projects" (such as MEDEA, DNA) and "umbrella projects", such as FAMOS, This aimed at developing pilot systems/plants.

The total investment up to now is about 20 BEuro.

EUREKA currently has 34 full member countries.

The EUREKA projects are market oriented. They are proposed (bottom up approach) by consortia composed of technology suppliers, end users, research institutions.

EUREKA FAMOS [87] launched 36 projects of which 29 aiming at flexible automated pilot systems/plants and 7 aiming at specific ETs. The estimated cost was 600MEURO, with 184 partners, from 18 countries, covering 17 industrial sectors.

\section{Manufacturing RTD Programmes in China}

The First Chinese government programme (the "National Programme for Key S\&T Projects") started in 1982 as a critical component of the five-year plans for the national economic and social development. The objective of the programme is to find solutions to the scientific and technological bottlenecks in the national economic and social development.

The programme is funded by both the central and local governments, and supplemented by financial inputs from different industrial sectors and institutions. The government investment on the programme during the Eighth Five-year Plan period (1991-1995) was about 4 billion Euro.

The National High Technology R\&D Programme Launched in 1986 was designed to pool the best technological resources in China for the purpose of keeping up with the world's high technology advances in certain fields, aiming at closing the gap between China and other countries in several critical areas

The National Programme for Key Basic Research Projects was initiated in 1991. The programme is designed to conduct high quality research on major scientific issues that have an important bearing on the nation's science and technology, as well as economic and social development, aiming at bringing great contributions to the national and world's scientific advances and social progress.

\section{Global Initiatives: the IMS programme}

More than 10 years ago the IMS programme [88] started based on an idea of Prof. Yoshikawa. It provides an example of a supranational program aimed at analyzing the existing NEST context and trends to asses future scenarios and corresponding enablers to be developed in targeted research projects that are consequently supported. It hence represents a valuable further example to complete the overview on existing research programs and the role they play in the R-I VC.

Seven different regions (Australia, Canada, the European Union and Norway, Japan, Korea, Switzerland, USA) participate in the programme, with a total value of endorsed projects of about 250 MEuro.

In the years 2000 and 2003 a vision assessment was performed. A summary with some interesting evaluations are given as follows.

- The boom goes on and on (in the year 2000).

- scenario appears to project current trends (Is the boom confined to certain sectors and types of firm? How to make other sectors and SMEs become knowledge-based?);

- Al redefined as knowledge based decision logic tools which could help to sustain the boom; 
- Hard times are here again (in the year 2003).

- stock market collapse will have disproportionate effect on technology utilization;

- risk to financial system through hacker attack needs to be met by ongoing development of security \& encryption technologies;

- threat to distributed manufacturing;

- We all got too warm (future).

- planet friendly technologies available now but sociopolitical barriers, reluctance to abandon sunk costs;

- need political framework, e.g. for cross-border recycling;

- easier to comply if manufacturers retain ownership of hardware through whole life and provide as Service;

- importance of IT/sensors to monitor.

Such assessments resulted in RTD projects supported in different areas, referring to different TPs and addressing relevant ETs according to the above vision. This is summarized in Table 12, mapping 9 of the 12 projects completed since 1992, while 19 additional projects have been endorsed and 8 more are endorsement pending.

\begin{tabular}{|c|c|c|c|}
\hline Acronym & Areas & TPs & ETs \\
\hline GNOSIS & J, EU, CDN, CH & All & E/O \\
\hline MISSION & J, EU, USA & Design & E/O \\
\hline TES & J, EU, AUS, USA & Dismissal & TT \\
\hline SIMON & EU, CDN, USA, J & Production & TT, C \\
\hline HUTOP & J, EU, CDN, CH & $\begin{array}{c}\text { Design, } \\
\text { Production }\end{array}$ & $\begin{array}{c}\text { TT, } \\
\text { M\&S, }\end{array}$ \\
\hline GLOBEMEN & AUS, EU, J, CH & Distribution & M\&S \\
\hline INTELLIWOOD & EU, USA, AUS & Use/maint. & M\&S \\
\hline $\begin{array}{c}\text { GLOBAL } \\
\text { CAPE-OPEN }\end{array}$ & EU, USA, J & Production & M\&S \\
\hline 3DS & USA, EU, J & Design & M\&S \\
\hline
\end{tabular}

Table 12: Examples of projects supported by the interregional IMS Programme, specified in terms of TPs and

ETs (legenda: TT: Transformation Technology; C:

Controls; M\&S: Machinery \& Systems; E/O: Enterprise/Organization)

\section{Some conclusions}

The previous analysis showed the support that Governments provided to RTD manufacturing programmes and Initiatives. This support concerned:

- different paradigms -among those studied in paragraph 3.1- from Flexible Automation to the incoming Sustainable Production;

- different Transformation Processes (TPs) and Enabling Technologies (ETs), covering from Transformation Technologies to machineries, systems and controls, from components to the extended factory level.

With the help of such programmes, manufacturing has reached a technological capability never achieved before in human history.

Now new challenges (driven by man's needs and NEST context changes) call for a new global effort, to be promoted by Governments as well as industry, to support the development of new paradigms and related TPS/ETs by investing in RTD for advanced knowledge based manufacturing.

\section{FLEXIBLE AUTOMATION: TOWARDS NEW PARADIGMS}

In the excursus for the study of the present and future of Flexible Automation, we have first described the macro components of the model, pulled by the NEST context and its variations, that generate "demand paradigms" (paragraph 2). Then, we have shown that industry, supported by education, as well as the R\&D process (R-I VC), copes with them through "response paradigms".

After that, we have assessed the historical evolution of the highlighted demand-response mechanism (paragraph 3), describing the paradigms that rose during the years and the evolution that lead to the paradigm of Flexible Production. This is now evolving towards such new concepts as Mass Customization and Sustainable Production. Besides the general conceptual level, the analysis has been conducted at an operational level, where different "responses" rose under the impulse of Flexible Automation.

We can now focus the analysis on the possible future evolutions and needs, both at a conceptual and at an operational level.

To this aim, a survey concerning the present and future of Flexible Manufacturing Systems (FMS) is presented, approaching such an issue at an operational level.

Then, future general scenarios will be assessed through the analysis of foresight activities conducted in different relevant areas (USA, EU), providing higher-level indications.

It will be possible, then, to draw some conclusions about the future of Flexible Automation.

\subsection{FMS Survey Results}

At an operational level, several field studies about FMS performances have been carried out in the last decade. To deepen and update the analysis, within the CIRP Working Group A/M/O on "Flexible Automation - Assessment and Future" a new survey [89] was conducted by Koren and Boër to analyse some experiences concerning the current use of Flexible Manufacturing Systems (FMS) and the degree of satisfaction currently achieved, aiming at stating relevant directions for future evolutions.

Several companies where asked to provide information about:

- the type of flexible system they installed;

- their experience with the system;

- the most relevant future directions of development.;

The most relevant findings can be summarised in the following points:

- Respondents were equally divided whether FMSs were being operated close to their potential performance (41\% YES; $41 \%$ NO) and whether FMS's performance had met their expectations ( $35 \%$ YES; $25 \%$ NO). $20 \%$ of FMSs failed and are not currently utilised.

- The industry is very dissatisfied with the initial capital investment in FMSs, and is not pleased with the cost of maintenance.

- Industry is purchasing more capacity and functionality than initially needed. This extra capacity was never utilised in $20 \%$ of the cases, and the extra functionality was never utilised in $30 \%$ of the cases.

- Although industry is interested in adding more capacity and functionality into the exiting system, they consider FMSs to be an expensive solution.

Provided these findings, the respondents indicated such major areas that require research as Reconfigurable Systems, maintenance, operating systems with multiple products and workforce training. Some other areas that 
require research were indicated: system throughput, reduction in ramp-up time, flexible fixtures, opencontrollers, high-speed machining.

Based on the obtained results, conclusions were drawn inside the working group concerning the most relevant topics to be addressed in the future. In particular, such major research topics were indicated as system cost (as this resulted to be by far the most important factor in future success of large manufacturing systems) and system reconfiguration capabilities (as this was the second ranked important issue, including machine modularity and ease of upgrading system capacity or to new technologies). Consequently, future research should be focused on:

- reduction of system cost;

- Design of system for reconfiguration;

It is important to notice that the emphasis on cost and their occurring in system reconfigurations shifts the attention on the management of the entire lifecycle of manufacturing systems, which is the direction selected by the model presented in paragraph 2 (see Figure 3).

To better highlight the indication for the future, hence, the structure of the questionnaire can be integrated into the proposed reference model described in Figure 1, and more specifically in the demand-response mechanism shown in Figure 3. The response, in fact, that a system can give to the request coming from an upper "stage" is just a part of its lifecycle, as it is also made of phases (such as design and implementation) occurring before the actual installation of the system, but deeply impacting the effectiveness of the response, as well. Thus the model can be used to thoroughly address the survey and hence obtain reliable indication about the future. The selected approach is summarized in Table 13.

\begin{tabular}{|l|l|l|}
\hline \multicolumn{2}{|c|}{ TOTAL NUMBER OF QUESTIONS } & $\mathbf{4 5}$ \\
\hline PRE-INSTALLATION & Design & 11 \\
\cline { 2 - 3 } & Implementation & 2 \\
\hline \multirow{2}{*}{ POST-INSTALLATION } & Use & 24 \\
\cline { 2 - 3 } & Reconfiguration & 8 \\
\hline
\end{tabular}

Table 13: Framework of the survey according to the developed reference model.

As a consequence, the results of the survey can be critically analysed as follows.

\section{Pre-installation indications}

Concerning the design phase (that is considered more in general, in this case, as system planning) it is possible to deduct the following main points:

- The systems in the sample are both installed to realize existing products and to produce new products (the first case may represent a reconfiguration of existing product/processes, in the second a new lifecycle starts).

- Before the installation, both over capacity and over functionalities (intended as system features) were planned in many cases. Planning over capacity is more common than planning over functionality. Among those who planned over capacity, those who actually exploited it balance those who did not exploit it. The extra capacity was never utilised in $20 \%$ of the cases, while the extra functionality was never utilised in $30 \%$ of the cases.

- The time to design the system is considered critical (even if less than expected).
- Machine modularity is a high priority expected outreach in the design phase.

Concerning the implementation phase it is possible to deduct two main points:

- There is a wide variety in the type of configuration installed. The Agile/FMS configuration is the most popular configuration being used.

- The time to install the system is considered critical.

Post-installation indications

Concerning the use phase it is possible to deduct:

- In most cases the system is used for the activities it was purchased for, indicating coherence between design and use.

- As an average, high satisfaction with the FMS in the sample is related to the increase in product variety, the reduction of changeover times and, partially, for the quality improvement.

- Those who believe the system is operated to its full potential balance those who think their systems are not operated at their full potential.

Eventually, concerning the reconfiguration phase it is possible to deduct that:

- The number of people who expect to purchase new FMS in addition to existing ones slightly exceeds the number of those who plan to expand the capacity of the existing systems, and these two options dominate the others.

- System reconfiguration capabilities as well as machine and control reconfiguration capabilities are ranked as higher priority features.

In summary, these indications can contribute to frame a picture of the current situation concerning Flexible Manufacturing Systems under lifecycle considerations. Both the specified findings and conclusions stress the necessity for a holistic approach covering the entire system life cycle, from design (design of systems for reconfigurations, system cost) to installation (system ramp up), from use (maintenance) to reconfiguration (Reconfigurable Systems).

The analysis of surveyed FMS performances and data as compared to Flexible Automation paradigms shows that there is a need to couple the drivers with the enablers very well in order to successfully implement innovative manufacturing technologies. The FMS survey shows that the users who were more careful in this analysis of driversenablers were also the mostt satisfied with the FMS implementations.

What is more, the survey highlights the necessity to focus on lifecycle efficiency, thus highlighting the ability to efficiently reconfigure the system due to changes in the context (which is the main feature of Reconfigurable Manufacturing Systems) as a major objective for the future.

\subsection{Foresight studies on Manufacturing: vision of the future}

Man-Industry Value Chain (M-I VC) will greatly change, in the next 15 years, due to man's needs and NEST context radical evolution. As described in paragraph 2.2, this will be supported by the R-I VC mechanism and its actors. Such changes, initially concerning "demand paradigms", will require new "response paradigms" and related TPs/ETs.

Following the model shown in Figure 4, this calls for foresight activities integrated by "roadmaps" to produce scenarios and, hence, contribute to develop or revise policy in terms of: 
- RTD goals, instruments, and procedures of public and private programmes;

- policy measures concerning framework conditions for "innovation" (science-society relations, industrial relations, human resources mobility, IPR, etc.).

Foresight and road mapping activities have been carried out by most of the advanced as well as some of the new emerging countries, covering several domains in the Ml$\mathrm{VC}$, from health needs to manufacturing [90], [91], [92], [93], [94], [95], [96], [97], [98], [99], [100], [101], [102], [103], [104], [105], [106], [107].

Two different approaches adopted, respectively, by the USA and the European Union are presented along with current results.

\section{USA approach}

The USA approach - bottom up, mainly industry lead but supported by Publish Institutions - is based on two main steps:

- Definition of a vision of the manufacturing enterprises of the future (NGM Project) and of its attributes, the corresponding required TPs and ETs, and the definition of the necessary R\&D activities.

- Definition of the future manufacturing technology requirements and outline solution paths to meet these requirements through "roadmaps" (IMTR Initiative).

The Next-Generation Manufacturing (NGM) Project was initiated in 1995 and started using a hierarchical format that first identified the global drivers of the new market place.

Following the work carried out by the NGM project (ended in 1997) the integrated Manufacturing Technology Roadmapping (IMTR) Initiative was launched (see paragraph 3.3) in 1998.

The IMTR developed a vision of the future manufacturing enterprises, focusing on how they will function internally as well as how they will interact with their customers, partners, suppliers, workforce and other stakeholders.

Using a structured methodology, the IMTR defined future manufacturing technology requirements and outlined solution paths to meet these requirements in four interrelated areas:

- Information Systems for Manufacturing Enterprises (IS);

- Modelling \& Simulation (M\&S);

- Manufacturing Processes \& Equipment (MPE);

- Technologies for Enterprise Integration (TEI);

Key aspects for the future identified by this vision are:

- integrated enterprise management;

- science-based manufacturing;

- intelligent process \& equipment;

- "plug and play" interoperability;

- flexible, distributed operations;

- fully integrated \& optimized design \& manufacturing;

Roadmaps have been developed within the four interrelated areas IS, M\&S, MPE, TEI.

Concerning the MPE area, in particular, the following main topics for the future of manufacturing were defined:

- zero net lifecycle waste;

- first part correct;

- intelligent control systems;

- innovative breakthrough processes (MEMS, bioprocessing);

- science based manufacturing;
- intelligent design and process advisors;

- knowledge repositories and validation centres;

- distributed control across extended enterprises;

- engineered materials and surfaces;

- freeform manufacturing;

\section{European approach}

The European Union DG Research, Directorate of Industrial technologies, commissioned a large foresight study FutMan to gain an updated and thorough strategic perspective of the future of manufacturing in Europe for the years 2015-2020 [91]. This is also in view of the next seventh Framework Programme.

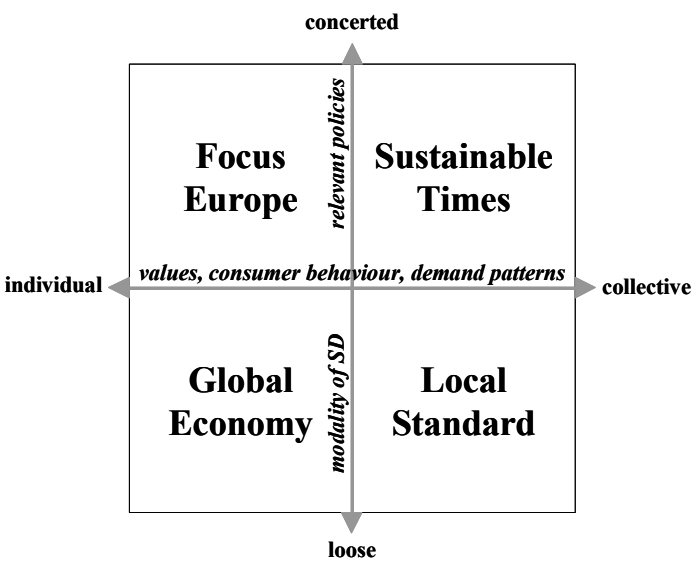

Figure 10: The scenarios on the future of manufacturing in Europe 2015-2020 (FutMan).

The scenarios shown in Figure 10 represent the general output of FutMan. This aims at offering imaginative pictures about potential socio-economic developments and future technologies that are likely to shape the European manufacturing sector over the coming years. The scenarios highlight important trends, possible trendbreaks, critical challenges and possible opportunities, and present four possible visions of manufacturing in Europe in the years 2015-2020. They map the space for sustainable development (SD) in the future.

The highlighted scenarios are structured around two qualitative dimensions of change. The first dimension relates to the kind of policy making, addressing the balance between public values and consumer attitudes.

The second dimension refers to the degree of integration of SD relevant policies, hence considering prevailing public values, consumer behaviour and demand patterns.

The socio-economic features of the four scenarios, dealing with the future of manufacturing in Europe in the years 2015-2020, are listed below:

- global governance;

- EU policy integration/ policy instruments;

- consumer behaviour/ values/ demand patterns;

- innovation policy focus;

- transport / energy infrastructure;

- sustainable development;

- education system;

- priorities in higher education;

- labour market;

- social security;

"Features" regarding industry, research institutions and RTD have been derived from the above four scenarios. Focusing on RTD, they may be summarised as follows: 
- sustainable technology development to strengthen competitive advantage in advanced manufacturing systems;

- flexible specialisation in design and manufacturing and more socially responsible production;

- new small production systems, specialised nanotechnology clusters;

Roadmaps are being produced to integrate the strategic foresight exercise.

The MANTYS Thematic Network [108], promoted by CECIMO (European Committee for Cooperation of the Machine Tool Industries), is generating insight into the mechanisms that relate technological innovation to socioeconomic factors. Building on this, it is identifying realistic scenarios based on likely technological and socioeconomical developments. These will be used to assess strategic impact.

Also, "Technology Roadmaps" are produced (i.e. Agile Enterprises, Next Generation Machine Tools) preparing decision makers to orient their activities and to adapt to change.

\subsection{Towards new Paradigms.}

The analysis, as carried out in chapter 3, connecting paradigms the NEST context they respond to, may be extended to the emerging scenarios. These may be considered as potential "demand" paradigms, which may drive the development of new of new " response " paradigms and related TPS/ETs and RTD actions and actors.

The two approaches described in paragraph 4.2 focus respectively on the company, to be "fit" to cope with the NEST context (as in the case of the USA approach) or on the NEST context, that needs to be foreseen (as in the case of the EU approach). Each of these approaches corresponds to two different environments.

NGM and IMTR Initiative were meant to help the Company to win in a difficult context, investing in RTD when needed.

On the other hand, FutMan and further activities will help to understand the NEST evolution, the role of Europe, future "demand" paradigms, and define RTD Programmes, besides involving the various actors and stakeholders. Both approaches lead to new emerging paradigms.

NGM proposes the "responsive" paradigm, covering from design to production.

FutMan shows the emergence of a paradigm combining sustainability and competitiveness, where flexile automation or rather reconfigurability may play a fundamental role.

Finally both approaches underline a new Industrial Paradigm, i.e.:

- current production and RTD based generation of new products and processes are two fundamental, integrated Company functions;

- networks of Companies and Networks of Research actors, may perform, respectively, the previous two functions, being integrated;

This emerging Industrial Paradigm may be called ManuFuture [109].

\section{RTD actors towards the future}

The competition for resources, the mechanisms to acquire them and the presence of new competitors on the research market are strong challenges for universities, research institutes and companies.

A strong selection may take place and change, in the next five to ten years, the international research landscape and market.
It is thus important -for universities and research institutes and centres involved in manufacturing RTD- to make a wide analysis, considering national and Regional situations and reviewing their goals and plans (i.e. assess their own sustainability), the output of which will be beneficial for them to eventually build up a truly sustainable RTD "fabric".

\section{CONCLUSIONS}

Manufacturing industry -covering man's needs/industry response Value Chain- has undergone several Revolutions in the last 50 years. They were driven by Natural, Economical, Social and Technological (NEST) context changes and based on RTD Innovation of paradigms, from Flexible Automation to Sustainable Production.

National and supranational RTD programmes have played a relevant role in promoting and supporting them. Focusing on production, the role of paradigms (conceptual level) and engineering solutions such as FMS (operational level) has been analysed.

Focusing on production processes and their life cycles, past and current production paradigms -from Flexible Automation to Sustainable Production- have been analysed and mapped. A good correlation between drivers and enablers has been described.

A survey concerning running FMSs has been carried out and the results reported. The analysis of surveyed FMS performances and data as compared to Flexible Automation paradigms shows that there is a need to couple the drivers with the enablers very well in order to successfully implement innovative manufacturing technologies. The FMS survey shows that the users who were more careful in this analysis of drivers-enablers were also the most satisfied with the FMS implementations.

Foresight studies, leading to NEST context scenarios, may help in defining the new paradigms required. Within the Man-Industry Value Chain (M-I VC), two domains have been considered:

- consumers and industry up-stream;

- man's life cycle needs/man focused services;

Emerging Transformation Processes TPs can be exploited in the future only through the development of innovative Enabling Technologies ETs in knowledge based manufacturing areas like new materials, nanotechnologies and micro \& hybrid devices.

The competition for resources, the mechanisms to acquire them, the presence of new competitors on the research market, is a strong challenge for universities, research institutes and companies. A strong selection may take place and change, in the next five to ten years, the international research landscape and market. This calls for the Sustainability of actors, as a fundamental prerequisite for the competitiveness and sustainability of industry.

Finally, the decreasing attention to manufacturing -while new needs and requirements are "springing up" which call for new RTD based "answers" from manufacturing -may lead to a strategic disaster [110].

New strategic RTD programmes should be launched.

\section{AKNOWLEDGEMENTS}

The authors are pleased to acknowledge the contribution of professor Uwe Heisel, professor Fritz Klocke, professor Toshimichi Moriwaki, professor Günther Seliger, professor Hans Peter Wiendahl, as well as the contribution by Dott. Ing. A. Urbani and several other members of the institute ITIA-CNR. 


\section{REFERENCES}

[1] EC, Workshop "The Machine-Tool sector and the FP6", Leuven - 25th October 2002

[2] Jovane, F., "Research based Evolution of the ManIndustry Value Chain", ITIA series, MRI, November 2002

[3] Federal information processing standard, December 1993, Integration Definition for Function Modelling (IDEF0), Publication 183

[4] Jovane, F., Carlesi, L., "The Elementary machine: an atomic model to analyze and device production systems" $39^{\text {th }}$ CIRP General Assembly, Trondheim August 1989

[5] Van Brussel, H., "Manufacturing paradigm shifts during 50 years of CIRP" Presidential address, Opening Session, 51th General Assembly, Nancy, France, 2001

[6] Dorf, R.C., Kusiak, A., (edited by), (1994), "Handbook of Design, Manufacturing and Automation"

[7] Pine, J.B., 1993, Mass Customization: The New Frontier in Business Competition, Harvard Business School Press, Boston, Mass., USA

[8] Boer, C.R., Jovane, F., 2002, Flexible and reconfigurable manufacturing automation for Mass Customization, Proceedings of the IFAC $15^{\text {th }}$ triennial world congress, Barcelona, Spain

[9] Gilmore, J. H., Pine, J. B., "Markets of one, creating customer-unique value through Mass Customization", Harvard Business School Press, 2000

[10] Tseng, M.T., Jiao, J., "Design for Mass Customization", Annals of the CIRP, Vol. 45/1, 1996

[11] Anderson, D. M., "Agile Product Development for Mass Customization: How to Develop and Deliver Products for Mass Customization, Niche Markets, JIT, Build to Order and Flexible Manufacturing", Irwin Professional Pub., 1997

[12] Tseng, M., Piller, F.T., "The customer centric enterprise, advances in mass Customization and personalization", Springer, 2003

[13] Goldman, S.L., Nagel, R.N., "Management, technology and agility: the emergence of a new era in manufacturing", International Journal of Technology Management, Vol. 8, No. 1/2, 1993

[14] Gunasekaran, A., "Agile manufacturing: enablers and an implementation framework", International Journal of Production Research, Vol. 36, No. 5, 1998, pp. $1223-1247$

[15] Lee, J., 1998, "Manufacturing Engineering in a Changing World: Issues, Challanges and Strategies", in International Journal for Manufacturing Science and Production, Vol. 1-3

[16] Newman, W.S., Podgurski, A., Quinn, R.D., Merat, F.L., et. al., (2000), "Design Lessons for Building Agile Manufacturing Systems", IEEE Transactions on Robotics and Automation, Vol. 16-3

[17] Duguay, C.R., Landry, S., Pasin, F., "From Mass Production to Flexible/Agile Production", International Journal of Operations \& Production Management, Vol. 17, No. 12, 1997, pp. 1183-1195

[18] Paolucci, F., "Design of a modular machine" Syndicate Groups : How to implement Agility Manchester 8th nov. 2001 -presentation for ECThematic Network (BRRT-CT98-5080) ARMMS Agile Reconfigurable Manufacturing Machinery Systems
[19] Wiendhal, H. P., Fiebig, C., Hernandez, R., 2002, “A transformable and reconfigurable factory: strategies, methods and case study", Proceedings of the ASME IMECE 2002, November, New Orleans, USA

[20] Klocke, F., "Changeability from the perspective of Technology" Presented at the STC "O" Meeting CIRP General Assembly, 2002

[21] Ashburn, A., "People and Automaton", American Mach. Automated Manufacturing, Vol. 130, No. 6, 97112, June 1986

[22] Emerson, C., "Detroit Style Automation", American Mach. Automated Manufacturing, Vol. 131, No. 7, 8192, July 1987

[23] Groover, M.P., "Automation, Production systems, and Computer Integrated Manufacturing, Prantice Hall, Inc., Englewood Cliffs, N.J, 1987

[24] Pessen, D., W., "Industrial Automaton", John Wiley and Sons, Inc., New York, 1989

[25] Raafat, F., "A comprehensive bibliography on justification of advanced manufacturing systems", International Journal of Production Economics Volume: 79, Issue: 3, October 11, 2002, pp. 197-208

[26] Ashley, S., 1997, Manufacturing Firms Face the Future, Mechanical Engineering, June, pp 70-74

[27] Sahin, F., 2000, Manufacturing competitiveness: different systems to achieve the same result, Production and inventory management journal, first quarter 2000

[28] Ranta, J., Tchijov, I., 1990, "Economics and Success Factors of Flexible Manufacturing Systems: the Conventional Explanation Revisited", in The International Journal of Flexible Manufacturing Systems, Vol. 2, pp. 169-190

[29] Benjaafar, S., Tirupati, D., 1998, "Introduction to the Special Issue of Manufacturing Flexibility", in The International Journal of Flexible Manufacturing Systems, Vol. 10, pp. 323-324

[30] Vessell, C., "Computer Integrated Manufacturing, and Small and Medium Enterprises", Computer and Industrial Engineering, Vol. 37, issue 1-2, October 1999

[31] Z., Y. Wanga; Rajurkar, K. P.a; Kapoor, A., "Architecture for agile manufacturing and its interface with computer integrated manufacturing, Journal of Materials Processing Technology Vol: 61, Issue: 1-2, August, 1996, pp. 99-103

[32] S. Kant Vajpayee, "Principles of Computer Integrated Manufacturing", Pearson Education POD; 1st edition, February 13, 1998

[33] Ayres, R.U., Dobrinsky, R., et al., "Computer Integrated Manufacturing", Chapman and Hall, 1992

[34] Shirinzadeh, Bijana, "Strategies for planning and implementation of flexible fixturing systems in a computer integrated manufacturing environment", Computers in Industry, Vol. 30, Issue: 3, October 15, 1996, pp. 175-183

[35] Michael L. George, "Lean Six Sigma : Combining Six Sigma Quality with Lean Production Speed", 2002

[36] Kevin J. Duggan, "Creating Mixed Model Value Streams: Practical Lean Techniques for Building to Demand", Productivity Press, New York, NY, 2002

[37] Schonberger, R. J., "Let's Fix It! Overcoming the Crisis in Manufacturing", The Free Press (a division of Simon \& Schuster, Inc.), New York, NY, 2001

[38] McCormack, R.A., "Lean Machines: Learning From the Leaders of the Next Industrial Revolution" 
[39] Pincelli, G., Borghi, L., Rusinà, F., "Evolution of Metal Working Strategies in the Automotive Industry: the High Speed Machining", Proceedings of the Dedicated Conference on Lean-Agile Manufacturing in the Automotive Industries, 1994

[40] Wiendhal H.-P., Helms K., Lutz S., (1999), „Supply Net - New Methods for Capacity Flexibilisation in Production Networks", Proc. 15 th Int.Conf. on Computer-Aided production Engineering, 609-610

[41] Childe S., (1998), "The extended enterprise - a concept of cooperation", Production Planning \& Control 9/4: 320-327

[42] Camarinha-Matos, L. M., Pantoja Lima, C., "A framework for cooperation in Virtual Enterprises", report from the European funded project PRODNET II, the ESPRIT project 22647

[43] Huang B., Gou, H.,et al., "A framework for virtual enterprise control with the holonic manufacturing paradigm", Computers in Industry, Vol: 49, Issue: 3 , December, 2002, pp. 299-310

[44] Xu, W., Wei, Y., Fan, Y., "Virtual enterprise and its intelligence management Computers and Industrial Engineering, Vol: 42, Issue: 2-4, April 11, 2002 Bibliographic Page, pp. 199-205

[45] Valckenaers, P., "Editorial of the Special Issue on Holonic Manufacturing Systems", Computers in Industry, Vol: 46, Issue: 3, October, 2001, pp. 233234

[46] Mathews, J., "Organizational foundations of intelligent manufacturing systems - the holonic viewpoint, "Computer Integrated Manufacturing Systems, Vol: 8, Issue: 4, November, 1995 Bibliographic Page, pp. 237-243

[47] Sun, H., Venuvinod, P.K., "The human side of holonic manufacturing systems", Technovation, Vol: 21, Issue: 6, June, 2001, pp. 353-360

[48] Fischer, K., "Agent-based design of holonic manufacturing systems", Robotics and Autonomous Systems, Vol: 27, Issue: 1-2, April 30, 1999 Bibliographic Page, pp. 3-13

[49] Huang B., Gou, H., et al., "A framework for virtual enterprise control with the holonic manufacturing paradigm", Computers in Industry, Vol: 49, Issue: 3, December, 2002, pp. 299-310

[50] Van Brussel, H., et al., "Reference Architecture for holonic manufacturing systems: PROSA", Computers in Industry, vol. 37, 1998, pp. 255-274

[51] Koren, Y., Heisel, U., Jovane, F., Moriwaki, T., Pritschow, G., Ulsoy, G., Van Brussel, H., 1999, Reconfigurable Manufacturing Systems, Annals of the CIRP, Vol. 48/2/1999

[52] Wiendhal, H. P., Fiebig, C., Hernandez, R., 2002, A transformable and reconfigurable factory: strategies, methods and case study, Proceedings of the ASME IMECE 2002, November, New Orleans, USA

[53] Son, S.Y., Olsen, T.L., Yip-Hoi, D., "Economic benefits of Reconfigurable Manufacturing Systems", Proceedings of the 2000 Japan USA Flexible Automation Conference, July 2000, Ann Arbor, Michigan

[54] Mehrabi, M., Ulsoy, G., Koren, Y., (1998) "Reconfigurable Manufacturing Systems: Key to Future Manufacturing", Proceedings of the JAPAN USA Symposium on Flexible Automation, Otsu, Japan

[55] Carpanzano E., Dallefrate D. and Jatta F. "Development of Self-reconfiguring, Manufacturing
Control Systems", SPIE Robotics \& Machine Perception, Vol. 12, N 1, March 2003, pp. 4-11

[56] Carpanzano E. and A. Cataldo. Modular design and simulation based verification of the logic control code for an agile shoe manufacturing system. Proc. Industrial Simulation Conference, ISC2003, EUROSIS, Valencia, Spain, June 9-11, 2003, pp. 290-294

[57] Dallefrate D., Carpanzano E. and Molinari Tosatti L. A reconfigurable numerical control algorithm for high speed machining (in Italian). Proc. International Conference on Automation within New Global Scenarios, Milan, Italy, November 19-21, 2002, paper 1.7

[58] Hagel, J., Brown, J.S., 2001, Your next IT strategy, Harvard Business Review, October, pp. 105-113

[59] Jovane, F., Spinolo, E., Martana, R., Research Project on "Automotive Components Service Manufacturing", PON, Ministry of Education, University and Research, November 2001

[60] Hibbard, J., 2002, Service Economy, Red Herring, February 2002, pp. 42-46

[61] Franke, C., Seliger, G., Hu, S, J., Koren, Y., "A new Paradigm of Manufacturing: selling use instead of selling systems", Proceedings of the JUSFA Japan USA Symposium on Flexible Automaton, July 17-22, Hiroshiima, Japan, 2002

[62] Urbani, A., Molinari Tosatti, L., Pasek, Z., 2002, Manufacturing practices in dynamic markets: reconfigurability to enable a service-based manufacturing capacity supply, Proceedings of the ASME-IMECE 2002, New Orleans, November 17-22

[63] Urbani, A. Colombo, C, "Analytical approach to the contract for the service supply of manufacturing capacity", Proceedings of the $34^{\text {th }}$ Cirp ISMS, Saarbrucken, Germany, June 2003

[64] Lay, G., Molinari Tosatti, L., Urbani, A., "New business paradigms for machinery, Build-OperateOwn or Service Manufacturing: New Challenge for European Machine Tool Builders", Track 4 preparation report: NEXT IP in EC VI FP Proposal

[65] Conklin, J.M., Perue, B.A., "Extending Capabilities Through Contract Manufacturing", ELECTRO INTERNATIONAL 1994, Boston, MA, May 10-12, 1994.

[66] Jovane, F. (edited by), Proceedings of the First international Forum on Sustainable Production: A New Industrial Growth, June 3, Venice, Italy, 1996

[67] Jovane, F. (edited by), Proceedings of the Second international Forum on Sustainable Production: The Role of Research, November 23-24, Venice, Italy, 1998

[68] Boër C.R. and Jovane F. (1996), "Towards a New Model of Sustainable Production: ManuFuturing", Annals of the CIRP, Vol.45/1/1996

[69] Knot, J. Marjolijn C.; van den Ende, Jan C.M.; Vergragt, Philip J., "Flexibility strategies for sustainable technology development", Technovation Volume: 21, Issue: 6, June, 2001, pp. 335-343

[70] Haner, Udo-Ernst, "Innovation quality-a conceptual framework", International Journal of Production Economics Volume: 80, Issue: 1, November, 2002, pp. 31-37

[71] Sarkis, Joseph, "Manufacturing strategy and environmental consciousness", Technovation Volume: 15, Issue: 2, March, 1995, pp. 79-97 
[72] Zhang, Hong C.; Kuo, Tsai C.; Huitian, Lu; Huang, Samuel H., "Environmentally Conscious Design and Manufacturing: A State-of-the-Art Survey", Journal of Manufacturing Systems Volume: 16, Issue: 5, 1997, pp. 352-371

[73] Craighill, A.L.; Powell, J. C., "Lifecycle assessment and economic evaluation of recycling: a case study", Resources, Conservation and Recycling Volume: 17, Issue: 2, August, 1996, pp. 75-96

[74] Dulio, S., Boer, C.R., "The road to shoe mass customisation calls for increased flexibility: the SPI 6 project", World Congress on Mass Customization and Personalization, Hong Kong, 2001

[75] EUROShoE Contract G1RD-cT-2000-00343, website www.euro-shoe.net

[76] Boer, C.R., Dulio, S., "The future of shoe Mass Customization as a perfect merge of old and new economy", World Congress on Mass Customization and Personalization, Hong Kong, 2001

[77] Wertheim, R., "Production research, an integral part of the manufacturing chain", Opening session, Presidential address $-52^{\text {nd }}$ general Assembly of CIRP, San Sebastian, Spain, 2002

[78] Moriwaki, T, Private communication

[79] MEP: Manufacturing Extension Partnership, http://www.mep.nist.gov

[80] NGM Next-Generation Manufacturing, A Framework for Action, Agility Forum, Leaders for Manufacturing and Technologies Enabling Agile Manufacturing, 1997. http://www.imti21.org/Documents/ngm.pdf

[81] IMTR, Integrated Manufacturing Technology Roadmapping Project, Technologies for Enterprise Integration, 3 December 1999. http://www.IMTI21.org

[82] Dalmiglio, D., Romano, P. Tagliaferri, C., "Analysis of EC Framework Programmes evolution", ITIA-CNR, Research Report 2003

[83] Wiendahl, H.P., Private communication

[84] Jovane, F., "Progetto Finalizzato Tecnologie Meccaniche: Relazione Finale”, CNR report 1990

[85] Cugini, U., Progetto Finalizzato Robotica: Relazione Finale", CNR report 1995

[86] EUREKA Secretariat Brussels, www.eureka.be, eureka.secretariat@es.eureka.be

[87] Jovane, F., "Results of the Eureka Famos Research Program: A European Contribution in Manufacturing Technology" Robotics and Computer Integrated Manufacturing, Vol 10, N. 1/2, pp. 13-15, 1993

[88] Boër C.R., Private communication: "IMS future: a summary of strategies from IMS Forum in 2000 and 2001", ISC-IMS, 2003

[89] Boër C.R., Koren, Y., "ERC/CIRP Survey on Flexible Manufacturing Systems", Working Group on "Flexible Automation - Assessment and Future" meeting, Paris, January 2003

[90] Martana, R., Jovane, F., "Evolving reference model for institutional research programmes and initiatives", ITIA-CNR Research Report, 2001

[91] EC - DG Research, "The Future of Manufacturing in Europe 2015-2020: The Challenge for Sustainable Development (FuTMan)", 2002

[92] Institute for Manufacturing - University of Cambridge, Department of Trade and Industry - UK Government department, INFORMAN 2000, Manufacturing Foresight Conference, Cambridge, UK, 12-14 March 2000

[93] International Technology Research Institute-World Technology (WTEC) Division, WTEC Panel Report on "Environmentally benign manufacturing", April 2001

[94] FIATECH, CAPITAL PROJECTS TECHNOLOGY : Technology Roadmap Initiative, March 2003

[95] European Science and Technology Observatory (ESTO) : Monitoring Foresight Activities, OST (France) and CEST (UK), coordinators with the contribution of VITO (Belgium), TNO and NRLO (Netherlands), VTT (Finland), FhG-ISI and VDI (Germany), ITA (Austria) - June 2001

[96] IMTI First Product Correct: Visions and Goals for the 21st Century Manufacturing Enterprise, Published by the IMTI Integrated Manufacturing Technology Initiative, - Inc. 2000

[97] IMTR Integrated Manufacturing Technology Roadmapping Project :Manufacturing Processes\& Equipment - 24 July 2000

[98] IMTR Integrated Manufacturing Technology Roadmapping Project: Manufacturing Success in the 21st Century: A Strategic View - 16 July 2000

[99] Agility Forum, Leaders for Manufacturing, and Technologies Enabling Agile Manufacturing: NextGeneration Manufacturing A Framework for Action Executive Overview - January 1997

[100] Agoria Mechanics \& Mechatronics sector roadmap. Building blocks for the future- 2002, RAND Publications SB-1072 : Critical Technologies - March 2003

[101] IMTI 21st Century Manufacturing Taxonomy: A Framework for Manufacturing Technology Knowledge Management V1.0 - Published by the IMTI Integrated Manufacturing Technology Initiative, - 12 December 2000

[102] Robert Phaal, Clare Farrukh and David Probert : Technology Roadmapping: linking technology resources to business objectives - Centre for Technology Management, University of Cambridge

[103] IMTR Integrated Manufacturing Technology Roadmapping Project : Technologies for Enterprise Integration - 3 December 1999

[104] A Trans-national Analysis of Results and Implications of Industrially-oriented Technology Foresight studies (France, Spain, Italy \& Portugal) :A joint JRC/IPTSESTO Study -February 2002

[105] PRU - Science and Technology Policy Research, University of Sussex: Foresight Futures 2020 Revised scenarios and guidance, UK, September 2002

[106] Department of Trade and Industry, "Foresight programme : Health care 2020", December 2000, UK.

[107] Lamarra, U., Pagani, M., "Manufacturing and biotechnologies: towards an integrated vision in Europe", ITIA-CNR, 2003

[108] MANTYS EC/VFP, "Thematic Network on Manufacturing Technologies: Technology Watch and Technology Foresight activities working documents", 2002/2003

[109] EC Conference, "ManuFuture 2003. European Manufacturing of the Future: role of research and education for European leadership", Milano, December 1-2, 2003

[110] U.S House of Representatives, Committee on Sciences, "Hearing on Manufacturing Research and Development", June 5th 2003, USA 